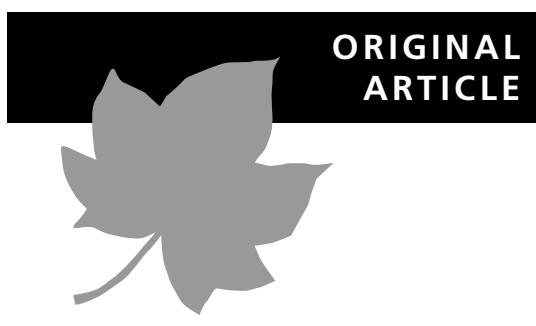

\title{
West Wind Drift revisited: testing for directional dispersal in the Southern Hemisphere using event-based tree fitting
}

Isabel Sanmartín ${ }^{1 \star}$, Livia Wanntorp ${ }^{2}$ and Richard C. Winkworth ${ }^{3}$

${ }^{1}$ Department of Systematic Zoology, Evolutionary Biology Centre, Uppsala University, Uppsala, Sweden, ${ }^{2}$ Department of Botany, Stockholm University, Stockholm, Sweden and ${ }^{3}$ Departamento de Botânica, Instituto de Biociencias, Universidade de São Paulo, São Paulo, Brazil
*Correspondence: Isabel Sanmartín. Department of Systematic Zoology, Evolutionary Biology Centre, Uppsala University, Norbyvägen 18D, SE-752 36 Uppsala, Sweden.

E-mail: isabel.sanmartin@ebc.uu.se

\section{ABSTRACT}

Aim Recent studies suggest that if constrained by prevailing wind or ocean currents dispersal may produce predictable, repeated distribution patterns. Dispersal mediated by the West Wind Drift (WWD) and Antarctic Circumpolar Current (AAC) has often been invoked to explain the floristic similarities of Australia, South America and New Zealand. If these systems have been important dispersal vectors then eastward dispersal - from Australia to New Zealand and the western Pacific to South America - is expected to predominate. We investigate whether phylogenies for Southern Hemisphere plant groups provide evidence of historical dispersal asymmetry and more specifically whether inferred asymmetries are consistent with the direction of the WWD/AAC.

Location Southern Hemisphere.

Methods We assembled a data set of 23 published phylogenies for plant groups that occur in New Zealand, Australia and/or South America. We used parsimonybased tree fitting to infer the number and direction of dispersals within each group. Observed dispersal asymmetries were tested for significance against a distribution of expected values.

Results Our analyses suggest that dispersal has played a major role in establishing present distributions and that there are significant patterns of asymmetry in Southern Hemisphere dispersal. Consistent with the eastward direction of the WWD/ACC, dispersal from Australia to New Zealand was inferred significantly more often than in the reverse direction. No significant patterns of dispersal asymmetry were found between the western Pacific landmasses and South America. However, eastward dispersal was more frequently inferred between Australia and South America, while for New Zealand-South American events westward dispersal was more common.

Main conclusions Our results suggest that eastward circumpolar currents have constrained the dispersal of plants between Australia and New Zealand. However, the WWD/ACC appear to have had less of an influence on dispersal between the western Pacific landmasses and South America. This observation may suggest that differences in dispersal mechanism are important - direct wind or water dispersal vs. stepping-stone dispersal along the Antarctic coast. While our analyses provide useful preliminary insights into dispersal asymmetry in the Southern Hemisphere we will need larger data sets and additional methodological advances in order to test fully these dispersal patterns and infer processes from phylogenetic data.

\section{Keywords}

Antarctic Circumpolar Current, asymmetric dispersal, Australia, concerted dispersal, event-based tree fitting, Gondwana, New Zealand, Southern Hemisphere, southern South America, West Wind Drift. 
Make Westing! He hugged the Horn, and a dozen times lay hove to with the iron Cape bearing east-by-north, or north-north-east, a score of miles away. And each time the eternal west wind smote him back and he made easting.

(Make Westing by Jack London)

\section{INTRODUCTION}

Cladistic biogeography (Nelson \& Platnick, 1981; Humphries \& Parenti, 1999) and panbiogeography (Croizat et al., 1974; Heads, 1999; McCarthy, 2003) have traditionally viewed dispersals as rare, chance events that are incapable of producing shared distribution patterns. Instead, such congruent distribution patterns have been attributed to vicariance - large-scale geological events that influenced the distributions of multiple groups simultaneously. Vicariance hypotheses were also preferred because they were considered to be testable - congruent patterns of distribution were evidence of vicariance, whereas dispersal hypotheses were considered unfalsifiable since any distribution pattern could be explained by invoking a sufficient number of ad hoc dispersal events (Morrone \& Crisci, 1995).

In recent years, however, there has been increasing acceptance of the critical role of dispersal in shaping the present distributions of organisms (Winkworth et al., 2002b; McDowall, 2004; Sanmartín \& Ronquist, 2004; McGlone, 2005; de Queiroz, 2005). Molecular phylogenetic analyses for a growing number of plant and animal lineages suggest that many are too young to have been influenced by plate tectonics and that their current distribution patterns are better explained by dispersal (e.g. Baum et al., 1998; Renner et al., 2000; Waters et al., 2000; Buckley et al., 2002; Knapp et al., 2005). In addition, recent analyses of multiple phylogenies (e.g. Vences et al., 2001; Winkworth et al., 2002b; Sanmartín \& Ronquist, 2004) suggest that dispersal may also be capable of generating concordant distribution patterns across taxa if it is constrained by prevailing wind and ocean currents to occur repeatedly in the same direction and between the same areas. Indeed, palaeobotanical evidence (Pole, 1994, 2001) suggests that this type of 'concerted' dispersal may have played an important role in shaping the flora of New Zealand. The acknowledgment that dispersal can be a pattern-generating process rather than simply an incidental phenomenon has initiated a 'counterrevolution' in historical biogeography (McGlone, 2005; de Queiroz, 2005; Riddle, 2005).

Similarities between the floras of Australia, New Zealand and southern South America have been recognized for more than 150 years (e.g. Hooker, 1853). Cladistic biogeography explained these links by vicariance - a once widespread Gondwanan flora that became subdivided as the supercontinent broke apart starting in the Late Mesozoic (e.g. Skottsberg, 1960; Nelson \& Ladiges, 2001; Swenson et al., 2001). The most widely accepted palaeogeographical reconstructions suggest that New Zealand was the first landmass to break away about 80 million years ago (Ma), while Australia and South America remained connected across Antarctica until the opening of the South Tasman Sea (35-30 Ma) and the Drake Passage (30-
$28 \mathrm{Ma}$ ) (Veevers et al., 1991; McLoughlin, 2001). This vicariance scenario predicts a phylogeny in which New Zealand lineages diverge first, and South American and Australian lineages are sister to one another. However, phylogenies for Southern Hemisphere plants often indicate closer relationships between species from Australia and New Zealand (e.g. Linder \& Crisp, 1995; Winkworth et al., 2002b; Wanntorp \& Wanntorp, 2003) or between those from New Zealand and South America (e.g. Swenson \& Bremer, 1997; Renner et al., 2000; Winkworth et al., 2002b). Some authors have explained these links using alternative geological scenarios (e.g. Linder \& Crisp, 1995; McCarthy, 2003), but in many cases molecular divergence time estimates suggest that the current species diversity has arisen too recently to be explained by geological vicariance. Instead, these age estimates suggest the importance of more recent long-distance dispersal (LDD) events for explaining the distributions of Southern Hemisphere plants. Such dispersal events have often been attributed to the strong westerly wind and ocean currents - referred to as the West Wind Drift (WWD) and the Antarctic Circumpolar Current (ACC), respectively - that were established around Antarctica after the opening of the Drake Passage between South America and Antarctica in the Oligocene (e.g. Lockhart et al., 2001; Wagstaff et al., 2002; Winkworth et al., 2002a). If these prevailing eastward currents were responsible for mediating Southern Hemisphere dispersal, then we would expect that dispersal from west to east would be most frequent. For example, dispersal across the Tasman Sea would be expected to occur most often from Australia to New Zealand. However, to date there have been few attempts to specifically test for such patterns.

There is circumstantial evidence for LDD among the major Southern Hemisphere landmasses, and in particular between Australia and New Zealand. Records from New Zealand document the arrival of both abiotic (e.g. smoke and dust) and biotic (e.g. birds, insects, pollen, seeds and spores) material from Australia; presumably these were wind-blown across the Tasman Sea (Close et al., 1978). These records not only indicate the potential for long-distance dispersal but also suggest that the prevailing wind and ocean currents may have an important role in mediating movement around the Southern Hemisphere. Phylogenetic studies of Southern Hemisphere plant groups also often favour eastward dispersal between Australia and New Zealand. For example, phylogenies for Gnaphalieae (Asteraceae; Breitwieser et al., 1999) and Nothofagus (Nothofagaceae; Swenson et al., 2001) both suggest dispersal from Australia to New Zealand. However, a survey of phylogenetic studies by Winkworth et al. (2002b) suggested that the circumpolar currents are not an absolute constraint on dispersal direction. More specifically, this study indicates that LDD in various directions is required to explain the origins of the New Zealand flora and its links to other southern Pacific landmasses. More recently Sanmartín \& Ronquist (2004) explored dispersal asymmetry in the Southern Hemisphere using an explicit biogeographical analysis of 18 plant lineages. While this study is consistent with dispersal in various 
directions, it suggests that dispersal between the Southern Hemisphere landmasses has been asymmetrical. They found that trans-Tasman dispersal between Australia and New Zealand was predominantly in an eastward direction, whereas trans-Pacific dispersal between New Zealand and South America has more often been westward, against the prevailing wind and ocean currents. The pattern of asymmetry was only statistically significant for New Zealand-South American dispersal events, and Sanmartín \& Ronquist (2004) noted that larger data sets will be required to further test asymmetry in Southern Hemisphere dispersal patterns.

In the present study we combine the phylogenies used by Winkworth et al. (2002b) and Sanmartín \& Ronquist (2004) in order to further explore patterns of long-distance plant dispersal in the Southern Hemisphere. In particular, we test whether these phylogenies provide support for eastward asymmetry in LDD. We analysed phylogenies for 23 plant lineages using a recently developed event-based biogeographical method. Unlike cladistic approaches, event-based methods do not consider only vicariance but explicitly incorporate all the processes that might explain the observed distribution pattern (Ronquist, 1998, 2003a; Sanmartín, 2006). Each process is assigned a cost and the analysis involves finding the reconstruction with the lowest overall cost (Ronquist, 2003a). This approach has recently been used to identify biogeographical patterns across multiple phylogenies (Sanmartín \& Ronquist, 2004).

\section{MATERIAL AND METHODS}

\section{Parsimony-based tree fitting}

Parsimony-based tree fitting is an event-based approach for inferring historical biogeography (Ronquist, 2003a; Sanmartín \& Ronquist, 2004). The method attempts to fit an organismal phylogeny with terminal taxa replaced by geographical ranges (the taxon area cladogram or TAC) and an area cladogram describing the historical relationships between the geographical areas (the general area cladogram or GAC). This fitting procedure produces a reconstruction that specifies a set of ancestral distributions and biogeographical events that, given the GAC, provide an explanation of the observed distribution of the lineage. In parsimony-based tree fitting we consider four types of event - vicariance (v), duplication (speciation within the area, d), extinction (e) and dispersal (i). Each event is associated with a cost and the overall cost of a reconstruction is simply the sum of costs for the inferred events. For example, consider the TAC in Fig. 1(a), with five species (1-5) occurring

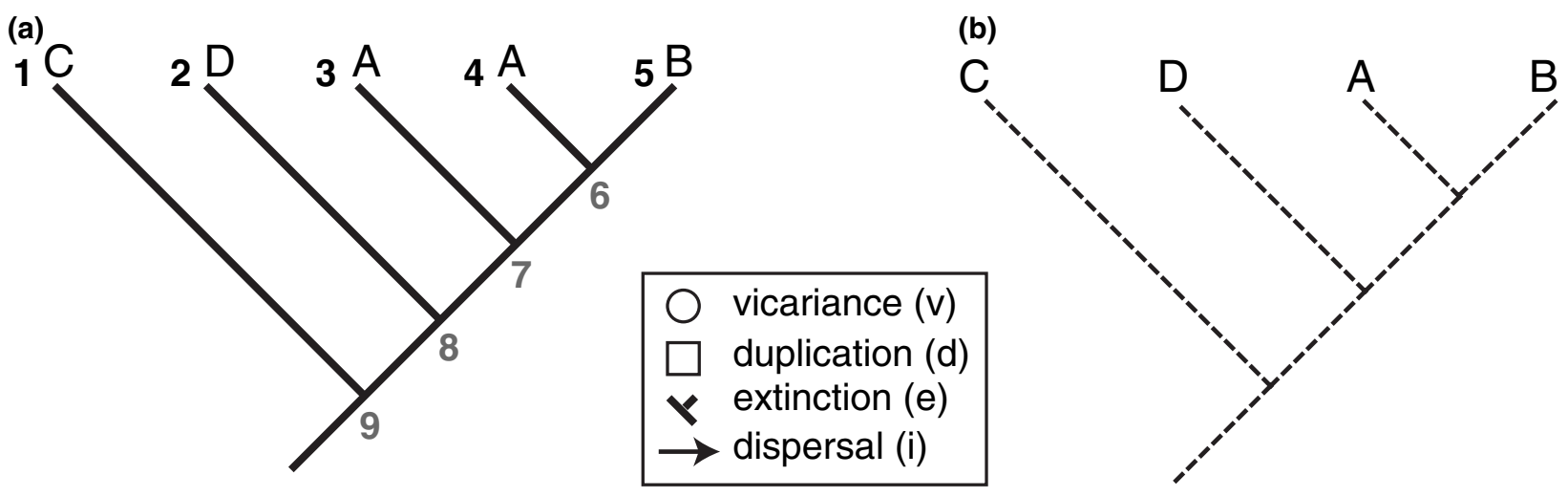

(c)

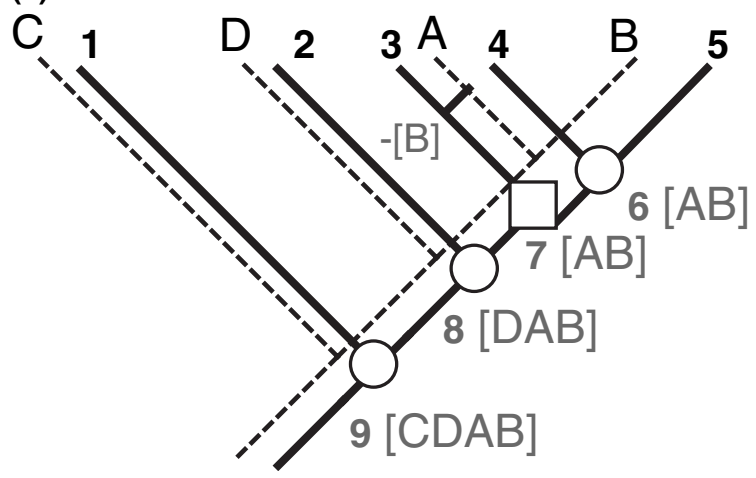

(d)

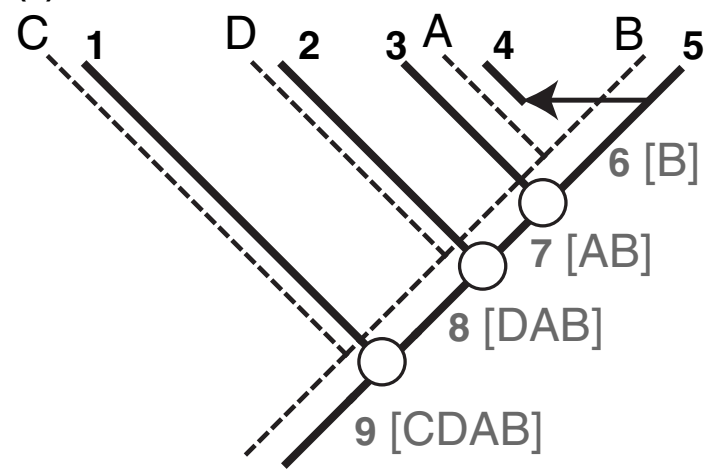

Figure 1 Parsimony-based tree fitting. (a) An organismal phylogeny and associated geographical distributions (TAC). (b) An area cladogram describing relationships between the areas (GAC). (c) One potential solution to fitting the TAC to the GAC. The cost of this reconstruction is $1 \mathrm{~d}+3 \mathrm{v}+1 \mathrm{e}=1.04$. (d) An alternative solution to fitting the TAC to the GAC. This reconstruction would be less parsimonious than that in $(\mathrm{c})$ since it costs $3 \mathrm{v}+1 \mathrm{i}=2.03$ (see text for discussion of cost assignment). 
in four areas (A-D), and the area cladogram GAC1 (Fig. 1b). In this case three vicariance events, a duplication and an extinction are required to explain the observed distribution pattern (Fig. 1c; total cost $=1 \mathrm{~d}+3 \mathrm{v}+1 \mathrm{e}$ ). However, there may be multiple ways to reconcile the TAC and GAC or several potential GACs that we wish to evaluate. For example, a potential alternative reconstruction is shown in Fig. 1(d). Here, the TAC is fitted to the GAC by a combination of vicariance and dispersal events (total cost $=3 \mathrm{v}+1 \mathrm{i}$ ). In parsimonybased tree fitting we are interested in identifying the most parsimonious reconstruction (i.e. that with minimum cost). Which of these reconstructions is the optimal solution depends on the specific value of the cost of individual events.

Event costs cannot be estimated directly from phylogeneticbased data using parsimony. Instead, Ronquist (2003a) proposed an optimality criterion for setting the event costs in parsimony-based tree fitting. This criterion assumes that we want to maximize the chance of finding 'phylogenetically constrained' distribution patterns (Ronquist \& Nylin, 1990; Ronquist, 2003a). That is, distributions which are determined by ancestor-descendant relationships within the phylogeny. Dispersal, duplication and vicariance may all lead to species formation. However, only duplication and vicariance have outcomes that are predictable in a phylogenetic context (Ronquist, 2003a). For example, in Fig. 1(c), species 1 and ancestor 8 arose following a vicariance event. The distributions of these two species (i.e. species 1 in area C; ancestor 8 in areas $\mathrm{A}, \mathrm{B}$ and $\mathrm{D})$ are non-overlapping subsets of the inferred ancestral distribution (i.e. ancestor 9 in areas A, B, C and D). Species 3 and 6, which arose as the result of duplication, both initially 'inherited' the entire range of the ancestor (i.e. ancestor 7 in areas A and B) although taxon 3 is later lost from area B. In both cases, the geographical range of the ancestor limits the possible distributions of the daughter lineages (Ronquist \& Nylin, 1990; Ronquist, 2003a; Sanmartín, 2006). Since vicariance and duplication lead to predictable 'ancestor-descendant' associations in geographical range, these events are referred to as being 'phylogenetically' or 'historically' constrained. On the other hand extinction and dispersal are considered to be 'historically unconstrained' since predictable ancestor-descendant associations do not result from these events (Ronquist \& Nylin, 1990). Dispersal leads to the colonization of an area that was not part of the ancestral range, while extinction reduces the ancestral range since the lineage disappears from one of the original areas. For example, in Fig. 1(d), species 4 arose following dispersal to area A. As a result, the geographical range of the descendants is expanded relative to that of the common ancestor - ancestor 6 occurred only in area B but its descendants occur in areas A (species 4) and B (species 5). In Fig. 1(c), although species 3 and ancestor 6 arose by duplication and originally shared the same distribution as their common ancestor, extinction of species 3 in area $B$ reduces the ancestral range and breaks the ancestor-descendant association.

We can test for constrained distribution patterns by randomly permuting the terminals in the TAC or the areas in the GAC, or both, and comparing the costs of reconstructions on these 'randomized' data with the cost of our 'observed' reconstruction. The optimal cost assignments are those that minimize the chance of the randomized data having a total cost that is equal to or lower than that of the observed cost. Examination of real and simulated data sets has shown that in order to find historically constrained distribution patterns, vicariance and duplication must have a lower cost than dispersal and extinction (Ronquist, 2003a). Moreover, Sanmartín \& Ronquist (2002) showed that dispersal must cost at least twice as much as extinction in order to minimize the effect of missing areas when analysing multiple TACs. Therefore in the program TREefitTer, which implements parsimony-based tree fitting, the default cost values are $\mathrm{v}=0.01$, $\mathrm{d}=0.01, \mathrm{e}=1$ and $\mathrm{i}=2$ (Ronquist, 2003b). Using these event costs, the reconstruction in Fig. 1(c) is the most parsimonious (total cost $=0.01+0.03+1=1.04$ ), since the alternative reconstruction (Fig. 1d) costs almost twice as much (total cost $=0.03+2=2.03$ ).

Widespread taxa (i.e. terminal taxa that are distributed in more than one area) pose a well-known problem in biogeographical analysis. Parsimony-based tree fitting provides three different options for dealing with this situation (Sanmartín \& Ronquist, 2002). These differ with respect to the assumptions they make about the origin of the widespread taxon - the recent option assumes that the widespread distribution is the result of recent dispersal, the ancient option assumes that it is ancestral and explains it by vicariance and extinction and the free option permits any combination of events to explain the widespread distribution. In an empirical study, Sanmartín et al. (2001) showed that the recent option has advantages over the free and ancient options when searching for constrained patterns. Assume that we test for constrained distribution patterns by comparing the cost of the observed TAC with that of randomized TACs obtained by shuffling the terminal distributions. The recent option allows only dispersal to explain the widespread terminals so vicariance events that might otherwise have been inferred to explain the widespread terminals are forced to internal nodes in the observed TAC. Since this is unlikely to occur in the randomized TACs, we can use this difference to distinguish phylogenetically constrained patterns from random patterns in this kind of test. In contrast, the ancient and free options will ignore this potential support because vicariance can be inferred to explain the widespread distribution. Consider the TAC in Fig. 2(a) where species 5 occurs in two areas, A and B. If we assume that the widespread species resulted from a recent dispersal, then either A or B is the ancestral area; the overall cost in each case depends on the relationships among the remaining taxa and the GAC. In this example, the minimum cost GAC would be $(\mathrm{B},(\mathrm{C},(\mathrm{D}, \mathrm{A})))$ because it requires only duplication and vicariance events (Fig. $2 \mathrm{~b}$; total cost $=2 \mathrm{~d}+2 \mathrm{v}=0.04$; notice that the terminal dispersal event is not included in the cost of the reconstruction as it is present for all GACs). In contrast, under the ancient option the optimal GAC is $(C,(D,(A, B)))$. Here, dispersal is not allowed to explain the widespread terminal and instead a 
(a)

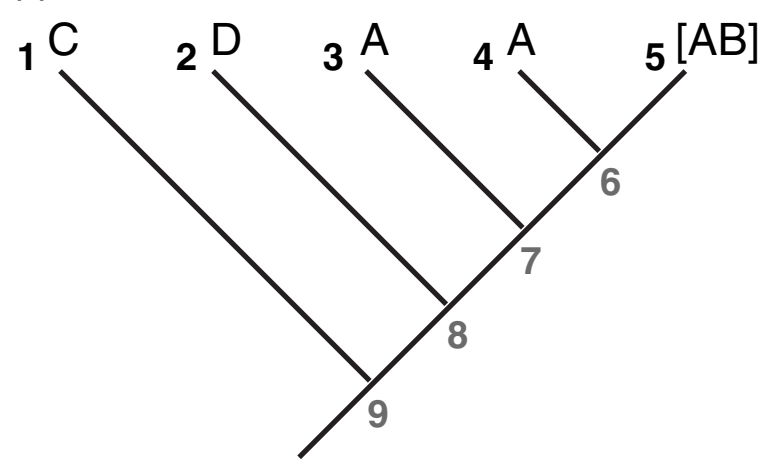

(b)

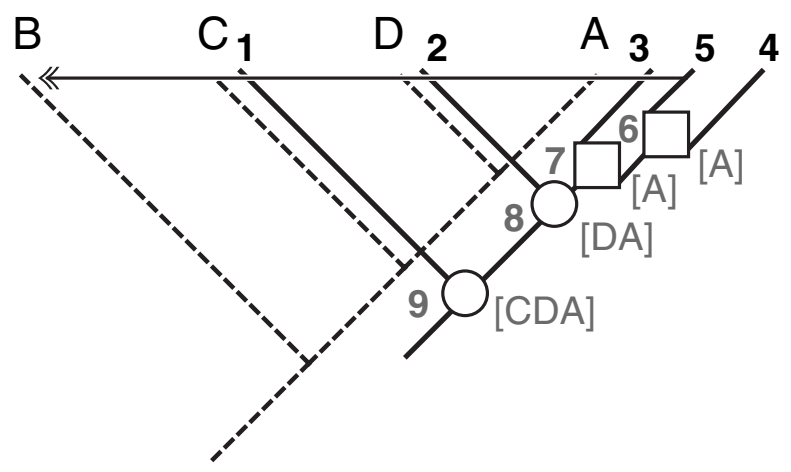

(c)

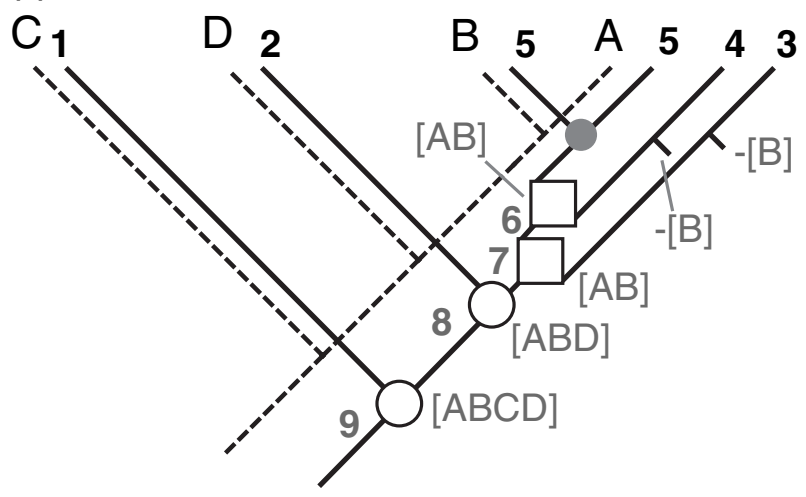

Figure 2 Widespread taxa in parsimony-based tree fitting. (a) A TAC with one widespread terminal (i.e. 5) that occurs in areas A and $B$. (b) The widespread terminal treated using the recent option and explained by recent dispersal (denoted by a double arrowhead). The minimum-cost GAC is $(B,(C,(D, A)))$ and the reconstruction has total cost $=2 \mathrm{~d}+2 \mathrm{v}=0.04$. (c) The widespread terminal treated using the ancient option and explained by vicariance (denoted by small grey circle). The minimum-cost GAC is $(\mathrm{C},(\mathrm{D},(\mathrm{B}, \mathrm{A})))$ and the reconstruction has total cost $=$ $2 \mathrm{~d}+2 \mathrm{v}+2 \mathrm{e}=2.04$. Notice that the cost of dispersal (recent option) and vicariance (ancient option) events within the widespread terminal are not included in the overall reconstruction cost since they would occur across all GACs. Event symbols, other than for events within the widespread terminal, as in Fig. 1.

terminal vicariance event coupled with extinction in the other terminals is inferred (Fig. 2c; total cost $=2 \mathrm{~d}+2 \mathrm{v}+$ $2 \mathrm{e}=2.04)$.

\section{Testing dispersal asymmetry}

Cook \& Crisp (2005a) have questioned the appropriateness of current tree-based methods for biogeographical inference because they ignore the potential influence of dispersal asymmetry. The impacts of unrecognized process asymmetry are well known in the context of ancestral character state reconstruction - assuming symmetry when an asymmetrical process exists results in incorrect inference of ancestral states, the number of transitions and their polarity (Cunningham, 1999; Ree \& Donoghue, 1999). In their paper Cook \& Crisp (2005a) consider an analogous situation in biogeography (Fig. 3). Here, a species from area $\mathrm{Z}$ is nested within a paraphyletic set of lineages that occupy area Y. Standard parsimony optimization, which assumes a symmetrical dispersal process, would reconstruct successive speciation events in area $\mathrm{Y}$ followed by a dispersal to $\mathrm{Z}$ (Fig. 3a). However, if dispersal is highly asymmetrical with movements from $Z$ to $Y$ three times more likely, then an alternative explanation is that $\mathrm{Z}$ is the ancestral area and each of the species in $\mathrm{Y}$ are the result of an independent dispersal event (Fig. 3b). In this case, if the dispersal asymmetry goes unrecognized the ancestral area is incorrectly inferred (i.e. $Y$ is reconstructed as ancestral rather than $Z$ ), the number of dispersals is underestimated (i.e. one dispersal is inferred instead of three) and the dispersal direction is incorrectly inferred (i.e. dispersal from $\mathrm{Y}$ to $\mathrm{Z}$ is assumed rather than the reverse). Cook \& Crisp (2005a) referred to this situation as a 'nested ancestral area' (NAA).

For any given area or lineage there will often be a large number of possible explanations for the origins of the current biota or distribution pattern. Among these there will be extreme scenarios that are difficult, if not impossible, to reconstruct accurately. The NAA situation is an example of an extreme scenario since the tree topology and extant species ranges provide no information about the distributions of the ancestral species - species 4 'inherited' the ancestral distribution but the remaining species (i.e. 1-3) all arose by dispersal so the ancestor-descendant geographical association is broken. In this case, no currently available method would provide an accurate reconstruction without additional information (e.g. an estimate of dispersal asymmetry). As described above, standard parsimony will fail to reconstruct the NAA scenario because a single dispersal to area $Z$ is more parsimonious than multiple dispersals from $Z$ to $Y$ under the assumption of symmetrical dispersal. Event-based methods (e.g. parsimony-based tree fitting) also assume symmetrical dispersal and will favour the standard explanation (total cost $=2 \mathrm{~d}+1 \mathrm{i}=2.02)$ over the NAA (total cost $=3 \mathrm{i}=6$ ). However, while extinction is ignored by the NAA scenario (Cook \& Crisp, 2005a), it is incorporated by event-based methods. Thus, in cases of high dispersal asymmetry, event-based methods will favour scenarios that involve widespread ancestors and extinction rather than repeated dispersal (Figs 3c, d). Maximum likelihood methods under both symmetrical and asymmetrical transition (dispersal) model will also fail to reconstruct the NAA scenario (e.g. Cook \& Crisp, 2005a). Moreover, Ree et al. (2005) have shown that for their likelihood method widespread 
(a)

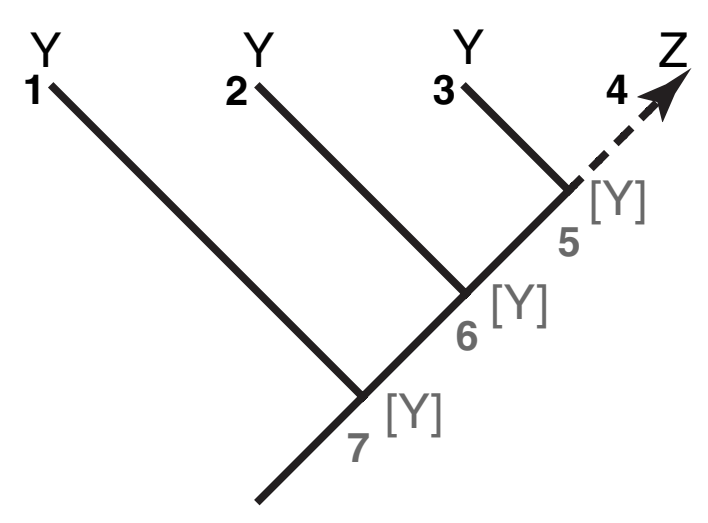

(b)

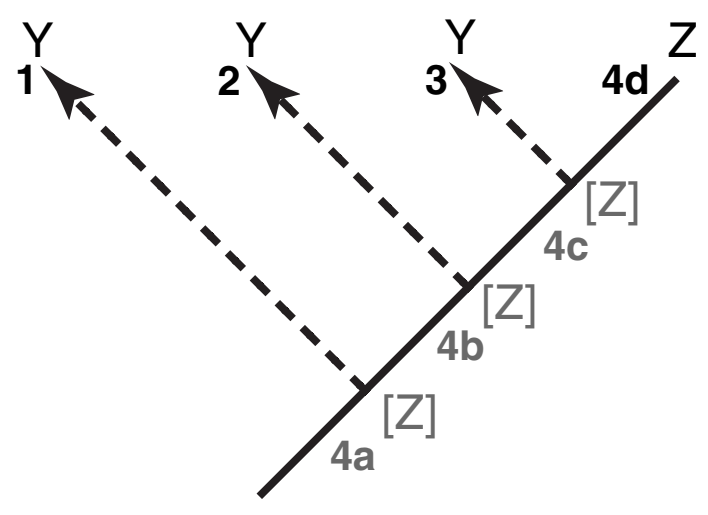

(d) (c)

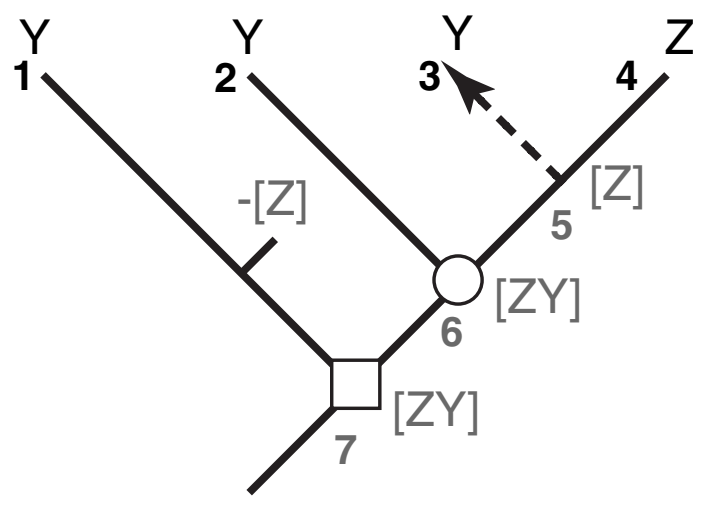

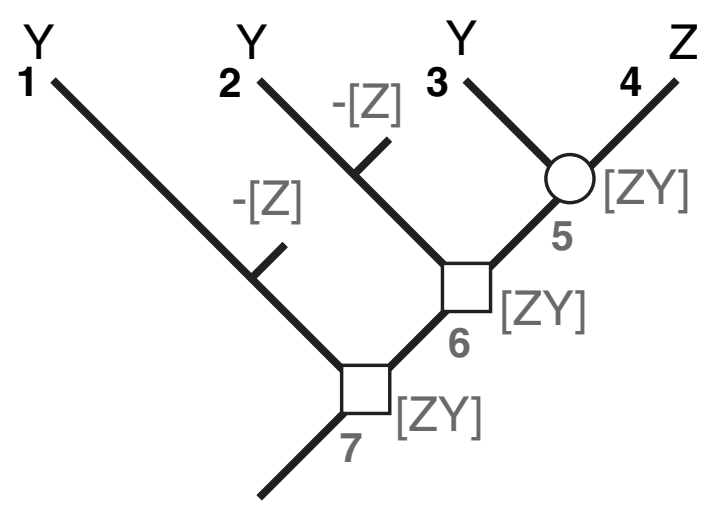

Figure 3 Dispersal asymmetry and tree-based biogeographical methods. (a) A TAC in which a single taxon from area Z (species 4) is nested within a paraphyletic group of lineages from area $Y$. The standard interpretation suggests duplication in area $Y$ followed by a dispersal from $Y$ to $Z$. In parsimony-based tree fitting this reconstruction would cost $=2 \mathrm{~d}+1 \mathrm{i}=2.02$. (b) The alternative 'nested-ancestral area' scenario proposed by Cook \& Crisp (2005a) that suggests repeated asymmetrical dispersal into area Y from an anagenetically evolving population in area Z. In parsimony-based tree fitting this reconstruction is less parsimonious, cost $=3 \mathrm{i}=6$. However, if dispersal is at least three times more frequent from $\mathrm{Z}$ to $\mathrm{Y}$ than from $\mathrm{Y}$ to $\mathrm{Z}$ and in the absence of extinction, this scenario will be more parsimonious than that in (a). (c), (d) If, as in parsimony-based tree fitting, extinction is considered then there are alternative more parsimonious reconstructions that require fewer $(c$, cost $=1 d+1 v+1 e+1 i=3.02)$ or no dispersal events $(d$, cost $=2 d+1 v+2 e=2.03)$. Event symbols as in Fig. 1.

ancestors will be favoured at ancestral nodes when dispersal is asymmetrical - a result similar to that of parsimony-based tree fitting.

The NAA scenario is clearly a difficult reconstruction problem and provides important insights into the limitations of our current methods and their assumptions. This scenario also highlights the important implications that dispersal asymmetry has for understanding historical biogeography. However, the NAA scenario is an extreme case of dispersal asymmetry and we question whether this pattern occurs frequently enough in nature to bias biogeographical inference. The scenario Cook \& Crisp (2005a) propose requires that within a single lineage there would potentially be many LDD events and that all the events would occur in the same direction. However, this does not fit well with our present general understanding of LDD. Current ecological models suggest that successful LDD is not a very common event and that dispersal direction is expected to exhibit at least some stochasticity (Nathan, 2006). It therefore seems more reasonable to expect one or a few successful events per lineage and to expect asymmetrical (although not unidirectional) processes to be most evident when dispersal is considered across multiple groups. Although there will be exceptions (e.g. ferns or orchids that will be very easily dispersed), what we suggest is that over evolutionary time dispersal has occurred often enough to explain current patterns but not so commonly or with such strong asymmetry as is suggested by Cook \& Crisp (2005a). It is also important to recognize that strong dispersal asymmetry alone is not sufficient to result in a NAA. As Cook \& Crisp (2005a) point out, maintaining a NAA requires a very delicate balance between speciation and dispersal. At the very least this scenario requires that: (1) the source population does not diversify (or alternatively that all new lineages in the source area go extinct), and (2) there is sufficient time between 
dispersal events for the daughter populations to become isolated. It may be possible to envisage a set of conditions that would allow the establishment and perhaps also the maintenance of an NAA. However, it remains questionable whether such conditions would be maintained long enough to influence all relevant nodes in the tree or whether these conditions would be general enough to influence entire plant assemblages (e.g. the flora of New Zealand). For example, for an NAA explanation to account for the current distribution of Hebe, the balance between speciation, dispersal and extinction would need to have been maintained over at least the last 4 million years (Myr) despite major climatic fluctuations of the Late Pliocene and Pleistocene. Based on our current understanding of dispersal and speciation processes it simply seems unlikely that the extreme NAA pattern would be common in nature.

Although the extreme scenario suggested by Cook \& Crisp (2005a) may be uncommon, detecting and accounting for dispersal asymmetry remains an important objective if we are to improve biogeographical inference. Certainly, if phylogenybased biogeographical reconstructions are to provide realistic descriptions then we need to incorporate estimates of dispersal asymmetry (Cook \& Crisp, 2005a). Unfortunately, our ability to estimate dispersal asymmetry is currently very limited. Except for large data sets we do not have appropriate methods for estimating asymmetry from phylogenetic data (Cunningham, 1999; Ree \& Donoghue, 1999). Furthermore, while the volume of phylogenetic data continues to grow, it may remain difficult to test certain scenarios since there are simply too few instances of dispersal to determine the significance of the inferred patterns. As Cook \& Crisp (2005a) point out, there are possible alternatives for estimating dispersal asymmetry. One potential source of information is population genetic data. However, for most lineages we currently lack appropriate data sets and in addition the interpretation of these data is not straightforward - populations exhibiting either the greatest (e.g. Juan et al., 2000) or least (e.g. Templeton, 1998) divergence have been interpreted as dispersed. More generally, the appropriate translation of asymmetry estimates into dispersal costs or likelihoods within a complete biogeographical model, that is one that includes extinction, requires much more work (F. Ronquist, personal communication). Cook \& Crisp (2005a) demonstrate that it is also possible to use sensitivity analyses to investigate the robustness of inferences based on the assumption of symmetry. While this approach provides useful insights, it is difficult to evaluate the results since we have no idea whether a particular weighting scheme represents a biologically reasonable level of asymmetry. There is certainly anecdotal evidence for dispersal asymmetry, but at this point applying a priori weighting schemes to account for dispersal asymmetry seems premature. This approach assumes an explanatory process that has not yet been established empirically - much like cladistic biogeography assumes vicariance - and may itself lead to incorrect biogeographical inference, the situation that it aims to avoid.

The importance of dispersal for shaping modern distribution patterns now seems to be well supported by molecular and fossil data, but we are only just beginning to test more detailed hypotheses. For example, to date there have been few attempts to test empirically for asymmetry in LDD (e.g. Sanmartín \& Ronquist, 2004). In the current study, we attempt to test whether dispersal asymmetry has been an important influence on patterns of distribution in the Southern Hemisphere. While we do not expect the problems associated with the extreme NAA scenario to be pervasive enough to influence our analyses, there are still statistical limitations to using current methods for testing dispersal asymmetry. Specifically, for parsimony-based tree fitting these are: (1) since vicariance and duplication have a lower cost than dispersal, the number of dispersal events may be underestimated, and (2) the level of asymmetry may be underestimated because the method assumes symmetric dispersal. As a result we expect the approach to be conservative. That is, to reject the occurrence of an asymmetric process when one is present (i.e. a Type II error). However, we favour this conservative approach since it allows us to be relatively confident if asymmetry is detected. Importantly, we view the current study as a preliminary assessment; we are trying to detect asymmetry in Southern Hemisphere dispersal patterns, more detailed studies will be necessary if we are to make specific estimates of the level of asymmetry.

\section{Analysis of Southern Hemisphere dispersal patterns}

We compiled a preliminary data set by combining the studies included by both Winkworth et al. (2002b) and Sanmartín \& Ronquist (2004). From this initial data set, we excluded 11 studies - seven used by Sanmartín \& Ronquist (2004) and four from Winkworth et al. (2002b) - because they either did not occur in the relevant areas (New Zealand and Australia and/or South America) or the phylogeny was not sufficiently resolved. We obtained the phylogenies either from the original references (or more recent studies when appropriate) or the data matrices of Sanmartín \& Ronquist (2004; available from http:// systematicbiology.org). Table 1 lists the final data set of 23 plant phylogenies along with references and, where available, age information based on fossil evidence or molecular divergence times. TREEFITTER requires fully resolved trees, so it was necessary to arbitrarily bifurcate organismal phylogenies for some groups prior to analysis. We treated the alternative resolutions in different ways. Where preliminary sensitivity analyses indicated that alternative resolutions did not alter the optimal solution, a single resolution was randomly selected or the polytomy summarized as a single terminal. In cases where the set of inferred events differed, all resolutions were included in the analysis. (e.g. for Carmichaelia three resolutions were included) Appendix S1 in Supplementary Material gives a list of the topologies used.

For our analyses, we defined five geographical areas: (1) Australia including Tasmania (AUS), (2) New Zealand including the Kermadec, Chatham and sub-Antarctic island groups (NZ), (3) southern South America including the southern temperate region (i.e. south of the Amazon Basin) as well as north-central South America west of the Andes 
Table 1 Taxa included in this study. For each group references to the original phylogenetic study as well as age information (where available) is given. Approximate ages are based on the earliest appearance of the group (SG) or a related taxon (RG) in the fossil record, and/ or on molecular divergence time estimates (MC). When fossil ages were given in terms of stratigraphy the midpoint of the geological interval is given (determined from Gradstein \& Ogg, 2004). The reference taxon is the group to which the age applies.

\begin{tabular}{|c|c|c|c|c|}
\hline Taxa & Original studies & Age (Ma) & Reference taxon & Supporting references \\
\hline Abrotanella (Asteraceae) & Wagstaff et al. (2006) & $\begin{aligned} & 42(\mathrm{RG}) \\
& 19.4(\mathrm{MC}) \\
& 4.2(\mathrm{MC})\end{aligned}$ & $\begin{array}{l}\text { Asteraceae microfossils } \\
\text { Stem clade } \\
\text { Crown group }\end{array}$ & $\begin{array}{l}\text { Macphail (1997) } \\
\text { Wagstaff et al. (2006) }\end{array}$ \\
\hline Aciphylla (Apiaceae) & Radford et al. (2001) & & & \\
\hline $\begin{array}{l}\text { Alseuosmiaceae- } \\
\text { Argophyllaceae- } \\
\text { Phellinaceae }\end{array}$ & Kårehed et al. (1999) & $82(\mathrm{SG})$ & Stem clade & Bremer et al. (2004) \\
\hline Aristotelia (Elaeocarpaceae) & Coode (1985) & * & & \\
\hline Atherospermataceae & Renner et al. (2000) & $\begin{aligned} 87 & (\mathrm{SG}) \\
82 & (\mathrm{SG}) \\
57-33 & (\mathrm{MC})\end{aligned}$ & $\begin{array}{l}\text { Atherosperm pollen } \\
\text { Atherospermoxylon } \\
\text { Laurelia-Laureliopsis }\end{array}$ & $\begin{array}{l}\text { Renner et al. }(2000) \\
\text { Poole \& Gottwald (2001) } \\
\text { Renner et al. }(2000)\end{array}$ \\
\hline Carmichaelinae (Fabaceae) & Wagstaff et al. (1999) & $\begin{aligned} 29 & (\mathrm{RG}) \\
2.5 & (\mathrm{SG}) \\
5 & (\mathrm{MC})\end{aligned}$ & $\begin{array}{l}\text { Astragalean clade } \\
\text { Carmichaelia } \\
\text { Swainsona-Clianthus }\end{array}$ & $\begin{array}{l}\text { Axelrod (1992) } \\
\text { Oliver (1928) } \\
\text { Lavin et al. (2005) }\end{array}$ \\
\hline Coriaria (Coriariaceae) & Yokoyama et al. (2000) & $\begin{array}{l}30(\mathrm{SG}) \\
60(\mathrm{MC})\end{array}$ & $\begin{array}{l}\text { Coriaria longaeba } \\
\text { Stem clade }\end{array}$ & $\begin{array}{l}\text { de Saporta (1865) } \\
\text { Yokoyama et al. (2000) }\end{array}$ \\
\hline $\begin{array}{l}\text { Corynocarpus } \\
\text { (Corynocarpaceae) }\end{array}$ & Wagstaff \& Dawson (2000) & $2.5(\mathrm{SG})$ & Corynocarpus pollen & Mildenhall (1980) \\
\hline Cunoniaceae & Bradford \& Barnes (2001) & $\begin{array}{l}82(\mathrm{SG}) \\
56(\mathrm{SG})\end{array}$ & $\begin{array}{l}\text { Weinmannioxylon } \\
\text { Eucryphia flowers }\end{array}$ & $\begin{array}{l}\text { Poole et al. }(2000) \\
\text { Barnes \& Jordan (2000) }\end{array}$ \\
\hline Cunonieae (Cunoniaceae) & Bradford (2002) & $82(\mathrm{SG})$ & Weinmannioxylon & Poole et al. (2000) \\
\hline Danthonia clade (Poaceae) & Linder \& Barker (2000) & $\dagger$ & & \\
\hline Gentianella (Gentianeaceae) & von Hagen \& Kadereit (2001) & $\begin{array}{l}1.6(\mathrm{SG}) \\
8-4(\mathrm{MC}) \\
5-3(\mathrm{MC})\end{array}$ & $\begin{array}{l}\text { Gentianella } \\
\text { Stem clade } \\
\text { Crown group }\end{array}$ & $\begin{array}{l}\text { van der Hammen (1979) } \\
\text { von Hagen \& Kadereit (2001) }\end{array}$ \\
\hline Gnaphalieae (Asteraceae) & Breitwieser et al. (1999) & & & \\
\hline $\begin{array}{l}\text { Hebe-complex } \\
\quad \text { (Scrophulariaceae) }\end{array}$ & $\begin{array}{l}\text { Wagstaff et al. (2002) } \\
\text { Wagstaff \& } \\
\text { Garnock-Jones (2000) }\end{array}$ & $\begin{array}{l}15(\mathrm{RG}) \\
2.5(\mathrm{SG}) \\
9.9(\mathrm{MC}) \\
3.9(\mathrm{MC})\end{array}$ & $\begin{array}{l}\text { Veronicastrum } \\
\text { Hebe pollen } \\
\text { Hebe clade } \\
\text { Hebe salicifolia lineage }\end{array}$ & $\begin{array}{l}\text { Tiffney (1985) } \\
\text { Mildenhall (1980) } \\
\text { Wagstaff et al. (2002) }\end{array}$ \\
\hline Korthalsella (Viscaceae) & Molvray et al. (1999) & & & \\
\hline Nothofagus (Nothofagaceae) & $\begin{array}{l}\text { Swenson et al. (2001) } \\
\text { Based on Manos (1997) }\end{array}$ & $\begin{array}{r}83.5(\mathrm{SG}) \\
93-83(\mathrm{MC}) \\
66-45(\mathrm{MC}) \\
45-30(\mathrm{MC}) \\
37-13(\mathrm{MC})\end{array}$ & $\begin{array}{l}\text { Nothofagidites pollen } \\
\text { Stem clade } \\
\text { Crown group } \\
\text { Subgenus Fuscospora } \\
\text { Fuscospora in NZ }\end{array}$ & $\begin{array}{l}\text { Dettmann et al. (1990) } \\
\text { Cook \& Crisp (2005b) }\end{array}$ \\
\hline Oreobolus (Cyperaceae) & Chacón et al. (2006) & $\begin{array}{r}6.5(\mathrm{MC}) \\
6(\mathrm{MC})\end{array}$ & $\begin{array}{l}\text { Crown group } \\
\text { Oreobolus pumilio-Oreobolus } \\
\text { venezuelensis clade }\end{array}$ & Chacón et al. (2006) \\
\hline Pittosporum (Pittosporaceae) & Gemmill et al. (2002) & & & \\
\hline Ranunculus (Ranunculaceae) & Lockhart et al. (2001) & $5(\mathrm{MC})$ & Basal radiation & Lockhart et al. (2001) \\
\hline $\begin{array}{l}\text { Rytidosperma } \\
\text { (Poaceae, Danthonieae) }\end{array}$ & Linder (1999) & $\dagger$ & & \\
\hline Stylidiaceae & Wagstaff \& Wege (2002) & $\begin{array}{l}39(\mathrm{SG}) \\
6(\mathrm{MC}) \\
2(\mathrm{MC})\end{array}$ & $\begin{array}{l}\text { 'Forstera'-type pollen } \\
\text { 'Forstera group' } \\
\text { Oreostylidium }\end{array}$ & $\begin{array}{l}\text { Macphail (1997) } \\
\text { Wagstaff \& Wege (2002) }\end{array}$ \\
\hline $\begin{array}{l}\text { Tetrachondra }+ \text { Polypremum } \\
\text { (Tetrachondraceae) }\end{array}$ & Wagstaff et al. (2000) & $\begin{array}{l}65(\mathrm{RG}) \\
37(\mathrm{MC}) \\
2.5(\mathrm{MC})\end{array}$ & $\begin{array}{l}\text { Apocynaceae } \\
\text { Tetrachondra-Polypremum } \\
\text { Tetrachondra hamiltonii- } \\
\text { Tetrachondra patagonica }\end{array}$ & $\begin{array}{l}\text { Muller (1981) } \\
\text { Wagstaff et al. (2000) }\end{array}$ \\
\hline Winteraceae & Karol et al. (2000) & $121(\mathrm{SG})$ & Winteraceae & Doyle (2000) \\
\hline
\end{tabular}

${ }^{*}$ Magallon et al. (1999) date Elaeocarpaceae as Paleocene (RG).

$\dagger$ Bremer (2002) dates Poaceae as $70 \mathrm{Ma}$ (MC). 


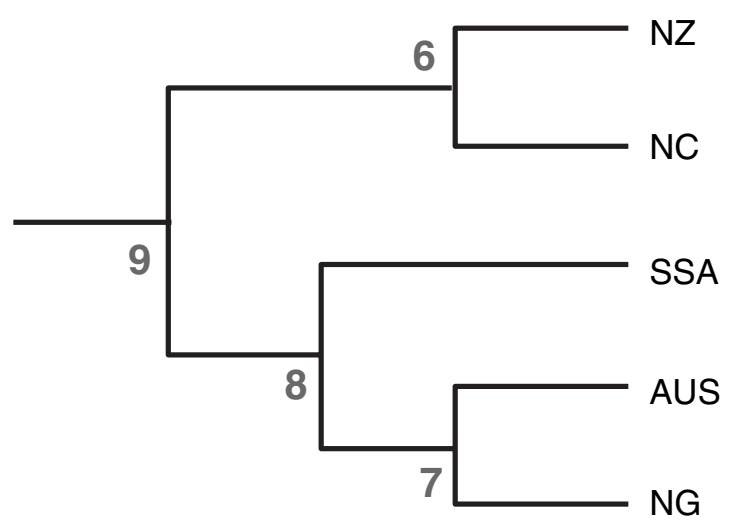

Figure 4 GAC representing the sequential break-up of East Gondwana. The cladogram describes the sequence of primary fragmentation. Numbers at nodes indicate vicariance events discussed in text. Area abbreviations: AUS, Australia; NC, New Caledonia; NG, New Guinea; NZ, New Zealand; SSA, southern South America.

(SSA), (4) New Caledonia (NC), and (5) New Guinea including New Britain, the New Hebrides, and Solomon Island groups $(\mathrm{NG})$. In several cases additional areas were represented in the organismal phylogenies but these are not explicitly considered during TREEFITTER reconstruction (see Appendix S1 for definitions of the areas). We used the conventional break-up pattern of Gondwana as the basis of our GAC (Fig. 4). There is uncertainty about the absolute timing of the geological events that underlie the isolation of the Southern Hemisphere landmasses. For example, the split between South America and Australia has been dated between $50 \mathrm{Ma}$, when a shallow seaway opened between Australia and Antarctica (e.g. Woodburne \& Case, 1996), and c. $30 \mathrm{Ma}$, when fully marine conditions were established between these landmasses (e.g. Veevers et al., 1991). However, since tree fitting is based solely on topology it is only necessary to consider the relative timing of the events. Most authors agree that New Zealand-New Caledonia split from Australia (node 9) prior to the separation of Australia and South America (node 8), and that this occurred before the Australia-New Guinea split (node 7). New Zealand and New Caledonia became isolated from one other (node 6) some time after splitting from Gondwana (node 9).

To estimate the extent to which the sequence of vicariance events in the geological GAC explains the distribution patterns in our data set, we fitted each organismal phylogeny to the GAC using the default cost settings of TREefitTer and the recent option to treat widespread taxa. We tested the significance of the fit by generating 1000 random data sets in which the areas in the GAC were randomly permuted. This test offers the most sensitivity for detecting vicariance patterns (Sanmartín \& Ronquist, 2004). We then calculated the cost of fitting the TAC to each of the randomized GACs. A significant match between TAC and Gondwanan GAC was accepted if for less than $5 \%$ of the randomized GACs the cost of fitting the TAC was equal to or lower than that of fitting the TAC to the Gondwanan GAC (i.e. $P<0.05$ ). For groups where information was available, we then compared the TREEFITTER reconstructions to age estimates (Table 1). This a posteriori filtering of the results helped us to determine whether treEFitTer had inferred any unlikely events.

Using the dispersal events inferred in the TREEFITTER reconstructions we tested for dispersal asymmetry both within individual groups and across the entire data set. For each lineage, we counted the number of dispersals inferred in each direction between New Zealand and Australia and between New Zealand and South America. Australia-South America dispersals were also counted, but we do not focus on these here since we excluded several of the phylogenies used by Sanmartín \& Ronquist (2004). As a result Australian-South American events are under-represented in our data set compared with the other dispersal types. We considered only 'ancestral' dispersals (i.e. not those within widespread terminals) and we averaged the number of inferred events for groups that were represented in analyses by multiple resolutions of the phylogeny. To test the significance of asymmetry in inferred dispersal we used a modified chi-square test to compare the observed frequencies with those expected by chance. The expected value and reference distribution for the chi-square test were obtained from a set of 1000 randomizations of the TAC (i.e. the terminals were randomly shuffled). An analogous procedure was used to test the significance of dispersal asymmetry across the entire data set (Sanmartín \& Ronquist, 2004).

\section{RESULTS}

None of the organismal phylogenies in our data set exhibited a significant fit to the Gondwanan GAC. This suggests that current distributions for these lineages cannot be fully explained by the break-up of the Gondwanan supercontinent. Although vicariance does not entirely explain the current distribution patterns, parsimony-based tree fitting infers vicariance events in several lineages (Table 2). In most cases the inferred events correspond to one of the more recent splits in the GAC. For example, vicariance associated with the Australia-New Guinea split was inferred for Corynocarpus, Cunoniaceae, Korthalsella and Rytidosperma. In contrast, TREEFITTER does not associate any lineage divergence events with the oldest vicariance event in our GAC, the separation of New Zealand-New Caledonia from the remaining landmasses. Specifically, vicariance is not inferred to explain the presence of these lineages in presentday New Zealand.

Consistent with earlier studies, our biogeographical reconstructions suggest that dispersal has played an important role in shaping current distribution patterns. Parsimonybased tree fitting infers dispersal events in 18 of the 23 phylogenies in our data set - in several cases multiple dispersals were inferred within a single lineage (e.g. Rytidosperma, Stylidiaceae) - and involving all three of the major 
Table 2 Vicariance and dispersals inferred from treefitter reconstructions. For vicariance the number of inferred events is in parentheses. For dispersal we give the observed and expected frequencies of dispersal events between New Zealand, Australia and South America for the individual lineages and across the whole data set. Statistically significant comparisons of dispersal asymmetry are marked in bold.

\begin{tabular}{|c|c|c|c|c|c|}
\hline & \multirow[b]{3}{*}{ Vicariance } & \multicolumn{3}{|c|}{ Inferred biogeographical events } & \multirow[b]{3}{*}{$P$} \\
\hline & & \multirow[b]{2}{*}{ Event type } & \multicolumn{2}{|l|}{ Dispersal } & \\
\hline & & & Observed frequency & Expected frequency & \\
\hline \multicolumn{6}{|l|}{ Individual groups } \\
\hline \multirow[t]{4}{*}{ Abrotanella } & & $($ AUS $\rightarrow \mathrm{NZ})$ & 0.250 & 0.611 & 0.502 \\
\hline & & $(\mathrm{NZ} \rightarrow \mathrm{AUS})$ & 2.250 & 1.889 & \\
\hline & & $(\mathrm{SSA} \rightarrow \mathrm{NZ})$ & 1.000 & 0.484 & 0.034 \\
\hline & & $(\mathrm{NZ} \rightarrow \mathrm{SSA})$ & 0.500 & 1.016 & \\
\hline \multirow[t]{2}{*}{ Aciphylla } & & $($ AUS $\rightarrow \mathrm{NZ})$ & 0.000 & 0.104 & 0.999 \\
\hline & & $(\mathrm{NZ} \rightarrow \mathrm{AUS})$ & 2.000 & 1.896 & \\
\hline Alseuosmiaceae & NZ/NC (2) & & & & \\
\hline \multirow[t]{2}{*}{ Aristotelia } & SSA/AUS-NG (1) & $(\mathrm{SSA} \rightarrow \mathrm{NZ})$ & 1.000 & 0.373 & 0.292 \\
\hline & & $(\mathrm{NZ} \rightarrow \mathrm{SSA})$ & 0.000 & 0.627 & \\
\hline \multirow[t]{4}{*}{ Atherospermataceae } & & $(\mathrm{SSA} \rightarrow \mathrm{NZ})$ & 1.000 & 0.637 & $>0.999$ \\
\hline & & $(\mathrm{NZ} \rightarrow \mathrm{SSA})$ & 0.000 & 0.363 & \\
\hline & & $($ AUS $\rightarrow$ SSA) & 1.000 & 0.830 & $>0.999$ \\
\hline & & $(\mathrm{SSA} \rightarrow \mathrm{AUS})$ & 0.000 & 0.170 & \\
\hline \multirow[t]{2}{*}{ Carmichaelinae } & & $(\mathrm{AUS} \rightarrow \mathrm{NZ})$ & 2.000 & 1.854 & 0.281 \\
\hline & & $(\mathrm{NZ} \rightarrow \mathrm{AUS})$ & 0.000 & 0.144 & \\
\hline \multirow[t]{2}{*}{ Coriaria } & & $(\mathrm{SSA} \rightarrow \mathrm{NZ})$ & 0.000 & 0.157 & 0.738 \\
\hline & & $(\mathrm{NZ} \rightarrow \mathrm{SSA})$ & 1.000 & 0.842 & \\
\hline \multirow[t]{2}{*}{ Corynocarpus } & NZ/NC (1) & & & & \\
\hline & AUS/NG (1) & & & & \\
\hline \multirow[t]{4}{*}{ Cunoniaceae } & AUS/NG (0-1) & $($ AUS $\rightarrow \mathrm{NZ})$ & 1.000 & 0.925 & $>0.999$ \\
\hline & & $(\mathrm{NZ} \rightarrow \mathrm{AUS})$ & 0.000 & 0.075 & \\
\hline & & $($ AUS $\rightarrow$ SSA) & 1.000 & 0.984 & $>0.999$ \\
\hline & & $(\mathrm{SSA} \rightarrow \mathrm{AUS})$ & 0.000 & 0.016 & \\
\hline \multirow[t]{2}{*}{ Cunonieae } & $\mathrm{NZ/NC}(0.5-1)$ & & & & \\
\hline & SSA/AUS-NG (0.5) & & & & \\
\hline \multirow[t]{2}{*}{ Danthonia clade } & SSA/AUS-NG (1) & $($ AUS $\rightarrow \mathrm{NZ})$ & 1.000 & 0.724 & $>0.999$ \\
\hline & & $(\mathrm{NZ} \rightarrow \mathrm{AUS})$ & 0.000 & 0.276 & \\
\hline \multirow[t]{4}{*}{ Gentianella } & & $(\mathrm{SSA} \rightarrow \mathrm{NZ})$ & 0.500 & 0.444 & 0.428 \\
\hline & & $(\mathrm{NZ} \rightarrow \mathrm{SSA})$ & 0.000 & 0.055 & \\
\hline & & $(\mathrm{AUS} \rightarrow \mathrm{SSA})$ & 0.000 & 0.147 & 0.185 \\
\hline & & $(\mathrm{SSA} \rightarrow \mathrm{AUS})$ & 0.500 & 0.352 & \\
\hline \multirow[t]{2}{*}{ Gnaphalieae } & & $($ AUS $\rightarrow \mathrm{NZ})$ & 5.500 & 2.815 & 0.065 \\
\hline & & $(\mathrm{NZ} \rightarrow \mathrm{AUS})$ & 0.500 & 3.185 & \\
\hline \multirow[t]{2}{*}{ Hebe } & & $($ AUS $\rightarrow \mathrm{NZ})$ & 0.500 & 0.068 & $<0.001$ \\
\hline & & $(\mathrm{NZ} \rightarrow \mathrm{AUS})$ & 0.500 & 0.931 & \\
\hline \multirow[t]{2}{*}{ Korthalsella } & AUS/NG (0-1) & $(\mathrm{AUS} \rightarrow \mathrm{NZ})$ & 1.000 & 0.736 & 0.999 \\
\hline & & $(\mathrm{NZ} \rightarrow$ AUS $)$ & 0.000 & 0.264 & \\
\hline \multirow[t]{2}{*}{ Nothofagus } & SSA/AUS-NG (3) & $($ AUS $\rightarrow \mathrm{NZ})$ & 2.000 & 1.509 & 0.838 \\
\hline & & $(\mathrm{NZ} \rightarrow \mathrm{AUS})$ & 0.000 & 0.489 & \\
\hline Oreobolus & & $($ AUS $\rightarrow \mathrm{NZ})$ & 1.000 & 0.837 & $>0.999$ \\
\hline & & $(\mathrm{NZ} \rightarrow$ AUS $)$ & 0.000 & 0.163 & \\
\hline & & $($ AUS $\rightarrow$ SSA) & 1.000 & 0.436 & 0.172 \\
\hline & & $(\mathrm{SSA} \rightarrow$ AUS $)$ & 0.000 & 0.564 & \\
\hline Pittosporum & NZ/NC (1) & & & & \\
\hline Ranunculus & & $($ AUS $\rightarrow \mathrm{NZ})$ & 0.000 & 0.062 & 0.999 \\
\hline & & $(\mathrm{NZ} \rightarrow$ AUS $)$ & 2.000 & 1.938 & \\
\hline
\end{tabular}


Table 2 continued

\begin{tabular}{|c|c|c|c|c|c|}
\hline & \multirow[b]{3}{*}{ Vicariance } & \multicolumn{3}{|c|}{ Inferred biogeographical events } & \multirow[b]{3}{*}{$P$} \\
\hline & & \multirow[b]{2}{*}{ Event type } & \multicolumn{2}{|l|}{ Dispersal } & \\
\hline & & & Observed frequency & Expected frequency & \\
\hline \multirow[t]{6}{*}{ Rytidosperma } & AUS/NG (1-2) & $($ AUS $\rightarrow \mathrm{NZ})$ & 3.500 & 1.758 & 0.204 \\
\hline & & $(\mathrm{NZ} \rightarrow \mathrm{AUS})$ & 1.250 & 2.992 & \\
\hline & & $(\mathrm{SSA} \rightarrow \mathrm{NZ})$ & 0.000 & 0.234 & 0.717 \\
\hline & & $(\mathrm{NZ} \rightarrow \mathrm{SSA})$ & 1.000 & 0.766 & \\
\hline & & $($ AUS $\rightarrow$ SSA) & 0.000 & 0.772 & 0.153 \\
\hline & & $(\mathrm{SSA} \rightarrow \mathrm{AUS})$ & 1.000 & 0.228 & \\
\hline \multirow[t]{6}{*}{ Stylidiaceae } & & $($ AUS $\rightarrow \mathrm{NZ})$ & 1.500 & 0.608 & 0.047 \\
\hline & & $(\mathrm{NZ} \rightarrow \mathrm{AUS})$ & 0.000 & 0.892 & \\
\hline & & $(\mathrm{SSA} \rightarrow \mathrm{NZ})$ & 0.500 & 0.137 & 0.116 \\
\hline & & $(\mathrm{NZ} \rightarrow \mathrm{SSA})$ & 0.500 & 0.863 & \\
\hline & & $($ AUS $\rightarrow$ SSA) & 1.500 & 1.376 & $>0.999$ \\
\hline & & $(\mathrm{SSA} \rightarrow \mathrm{AUS})$ & 0.000 & 0.124 & \\
\hline \multirow[t]{2}{*}{ Tetrachondra } & & $(\mathrm{SSA} \rightarrow \mathrm{NZ})$ & 0.500 & 0.500 & 0.999 \\
\hline & & $(\mathrm{NZ} \rightarrow \mathrm{SSA})$ & 0.500 & 0.500 & \\
\hline \multirow[t]{2}{*}{ Winteraceae } & $\mathrm{NZ/NC} \mathrm{(1)}$ & & & & \\
\hline & SSA/AUS-NG (1) & & & & \\
\hline \multicolumn{6}{|l|}{ ENTIRE DATA SET } \\
\hline \multirow[t]{2}{*}{ Trans-Tasman } & & $($ AUS $\rightarrow \mathrm{NZ})$ & 19.250 & 11.591 & $<0.001$ \\
\hline & & $(\mathrm{NZ} \rightarrow \mathrm{AUS})$ & 8.500 & 16.156 & \\
\hline \multirow[t]{4}{*}{ Western Pacific-South America } & & $(\mathrm{SSA} \rightarrow \mathrm{NZ})$ & 4.500 & 3.689 & 0.273 \\
\hline & & $(\mathrm{NZ} \rightarrow \mathrm{SSA})$ & 3.500 & 4.309 & \\
\hline & & $($ AUS $\rightarrow$ SSA) & 4.500 & 3.280 & 0.097 \\
\hline & & (SSA $\rightarrow$ AUS) & 1.500 & 2.720 & \\
\hline
\end{tabular}

Southern Hemisphere landmasses (Table 2). The frequent inference of dispersal to explain present-day distribution patterns is generally consistent with the available information on lineage ages (Table 1). Obviously the age information provided is imprecise in many cases, especially when dates apply to more inclusive groupings. However, we do not intend these data to be used for detailed biogeographical inference. Instead, by comparing our TREEFITTER reconstructions with age information we simply wish to evaluate whether the results are plausible. Consistent with our reconstructions, age information often suggests that present-day species diversity is relatively young and the current distributions are best explained by dispersal. This is particularly true for New Zealand taxa. Age information suggests that many of the groups in our data set are either too young to have been present in New Zealand before it was isolated from Gondwana (e.g. Oreobolus, Gentianella, Carmichaelinae) or, for groups that are old enough to have been present, extant representatives arose long after separation (e.g. Nothofagus, Atherospermataceae). Such a temporal distinction is more difficult for Australia-South America events but there are at least some groups that appear to be too young to be explained by vicariance (e.g. Gentianella, New Zealand-Stylidiaceae).

In most cases the individual biogeographical reconstructions suggested by parsimony-based tree fitting are consistent with previously suggested scenarios. For example, our analyses of Nothofagus (Fig. 5) suggest duplications prior to the separation of South America and Australia-New Guinea to explain the origin of the Lophozonia, Fuscospora and Nothofagus-Brassospora clades; the split between Nothofagus and Brassospora being explained by vicariance (the isolation of Australia-New Guinea from South America). In contrast, the extant species of Lophozonia (e.g. Nothofagus menziesii) and Fuscospora (e.g. Nothofagus fusca, Nothofagus solandri and Nothofagus truncata) in New Zealand are explained by recent dispersal from Australia. These inferred events correspond well with estimates of molecular divergence time that suggest the extant subgenera diverged 66-45 Ma, before Australia and South America split, and that the extant New Zealand species of Fuscospora and Lophozonia arose in the Late Tertiary, well after New Zealand rifted from Australia (Cook \& Crisp, 2005b; Knapp et al., 2005). For the Hebe complex, tree fitting suggests an all-dispersal explanation that is also consistent with molecular age estimates indicating that the group began to diversify no more than $10 \mathrm{Ma}$ (Fig. 6; Wagstaff et al., 2002). For this group, Cook \& Crisp (2005a) found that a standard parsimony optimization on the phylogeny of Wagstaff et al. (2002) reconstructed New Zealand as the ancestral area and therefore suggests dispersal from New Zealand to Australia. However, since the predominantly New Zealand Hebe and Australian Derwentia clades are recipro- 
Figure 5 TREEFITTER reconstruction for Nothofagus based on the phylogeny of Swenson et al. (2001). Subgenera marked by solid bars on the right. Confidence intervals on divergence time estimates are given for relevant nodes (based on Cook \& Crisp, 2005b). Area abbreviations as in Fig. 4.

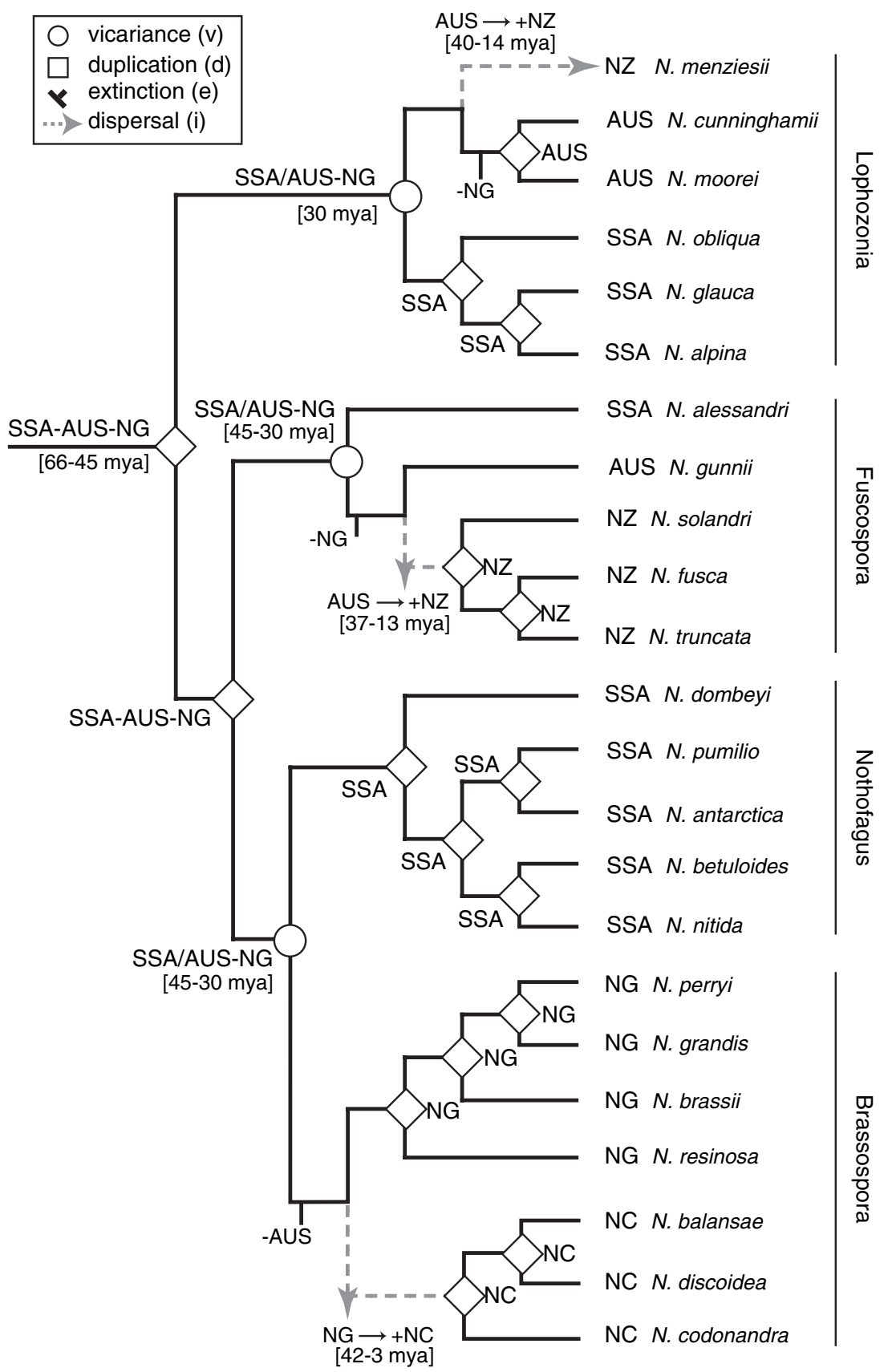

for the genus make it difficult to exclude alternative explanations involving dispersal between Australia-New Guinea or New Zealand-New Caledonia (Wagstaff \& Dawson, 2000). This example highlights problems associated with not explicitly incorporating age information into the reconstruction procedure - in some cases treefitter will infer events that are unlikely based on other lines of evidence. However, for our analyses this uncertainty is not critical since we are not concerned with these particular event types.

For individual lineages, trans-Tasman dispersal was most often inferred to be in an eastward direction - from Australia to New Zealand. However, this pattern of asymmetry was only significant for Hebe and Stylidiaceae (Table 2). Failure to 


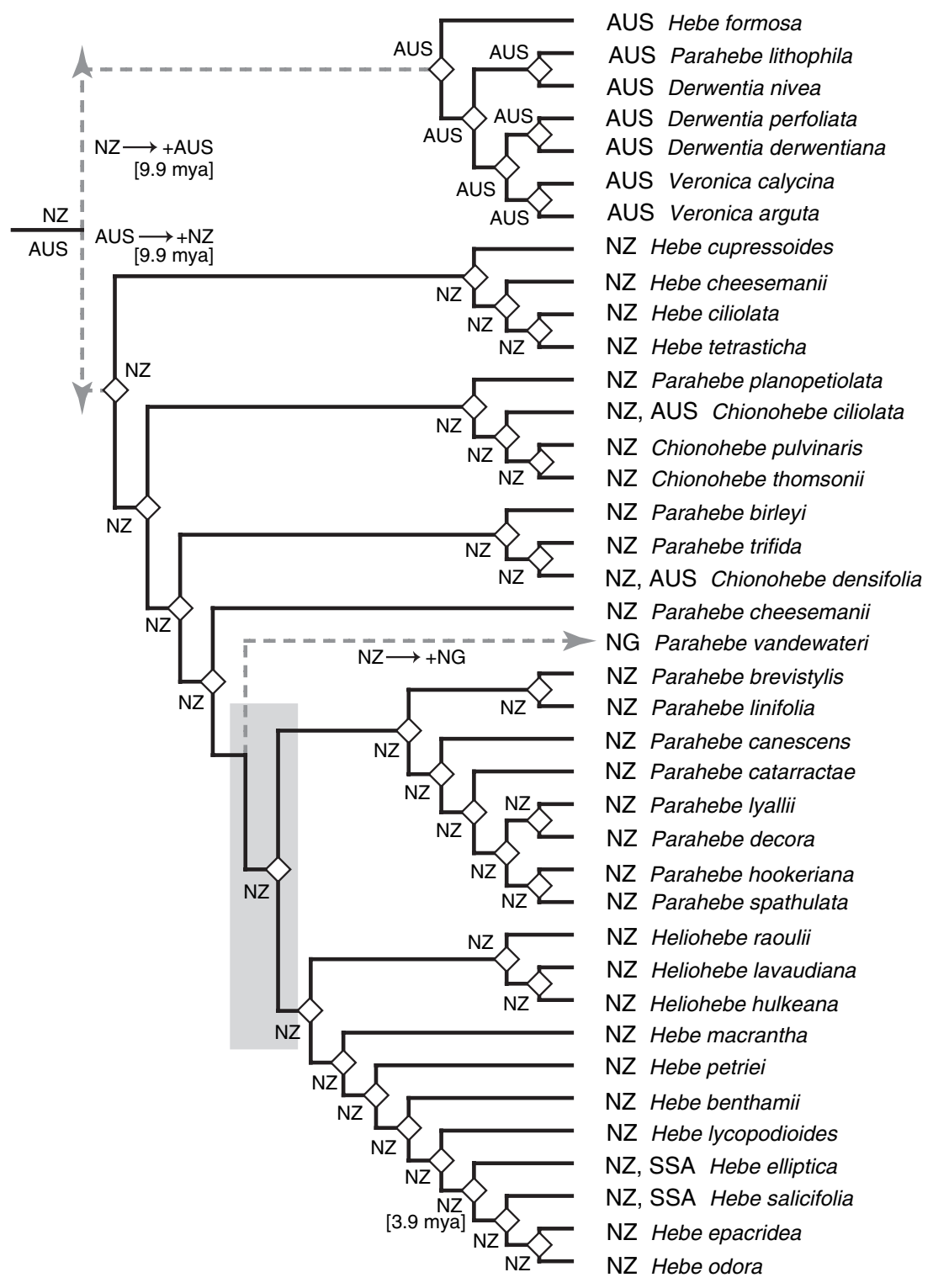

Figure 6 TREefitTer reconstruction for the Hebe complex based on the phylogeny of Wagstaff et al. (2002) but with additional resolution of relationships from Wagstaff \& Garnock-Jones (2000). The shaded box highlights a polytomy in the original tree that does not change the biogeographical reconstructions. Estimates of divergence times are given for relevant nodes (based on Wagstaff et al., 2002). Area abbreviations as in Fig. 4; event symbols as in Fig. 5. detect significance within individual lineages probably reflects the small number of inferred dispersals per group - individual phylogenies would probably not contain sufficient instances of dispersal to detect asymmetric character change with equally weighted parsimony (Cunningham, 1999). In contrast to individual analyses, we do detect a significant level of asymmetry in inferred trans-Tasman dispersal events when we consider the entire data set. Consistent with transport mediated by the WWD or ACC, inferred dispersals were more frequently from Australia to New Zealand than the reverse $(P<0.001$; Table 2). Inferred dispersals between New Zealand and South America occurred more frequently against the direction of circumpolar currents - that is from South America to New Zealand. This result is consistent with Sanmartín \& Ronquist (2004), but unlike these authors we did not detect a significant directional asymmetry in these events $(P=0.273$; Table 2). This difference may reflect the inclusion of a more recent molecular phylogeny for Abrotanella (Wagstaff et al., 2006). In this tree, the position of several key species differs relative to the morphology-based phylogeny of Swenson \& Bremer (1997) that was included by Sanmartín \& Ronquist (2004). As a result only a single dispersal event is now inferred. Dispersal between Australia and South America was more frequent in an eastward direction, although again the asymmetry was not statistically significant $(P=0.097$; Table 2$)$. Figure 8 illustrates patterns of dispersal asymmetry across the whole data set. Here, observed dispersal frequencies are normalized against the expected values (Wares et al., 2001) to correct for unequal representation of the areas in our data set.

\section{DISCUSSION}

The progressive break-up of Gondwana has often been suggested as a classic example of vicariance - the biotic links 


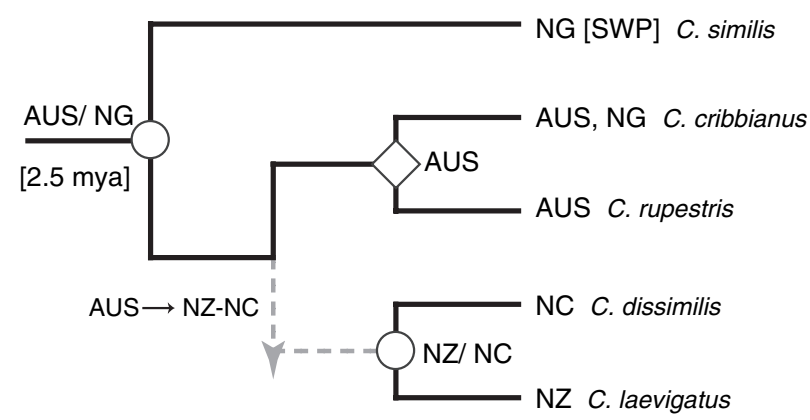

Figure 7 TREEFITTER reconstruction for Corynocarpus based on the phylogeny of Wagstaff \& Dawson (2000). Estimates of divergence times are given for relevant nodes (based on Wagstaff \& Dawson, 2000). Area abbreviations as in Fig. 4 with the addition of SWP, South West Pacific (this additional area is not considered during the treefitter analysis); event symbols as in Fig. 5.

between the present-day landmasses being assumed to reflect their ancient terrestrial links. However, at least for plants, molecular phylogenetic analyses and fossil data now indicate that LDD events have been important for shaping Southern Hemisphere distribution patterns. Here we have used a set of 23 phylogenies and parsimony-based tree fitting to test hypotheses about the mechanisms underlying Southern Hemisphere plant dispersal. We discuss our results in terms of possible dispersal modes and routes, and also prospects for the continued development of biogeographical methods.

\section{Concerted dispersal in the Southern Hemisphere}

\section{Trans-Tasman dispersal}

Various authors have discussed the role of eastward circumpolar currents in establishing and maintaining the biotic links between Australia and New Zealand - among the earliest are Hatch (1951, 1952), Fell (1962) and Raven (1973). Consistent with the suggested importance of circumpolar currents we find a significant eastward asymmetry in inferred transTasman dispersal. Based on corrected estimates the inferred frequency of dispersal from Australia to New Zealand was more than three times that in the reverse direction (21.1 vs. 6.70 events; Fig. 8). In their earlier study, Sanmartín \& Ronquist (2004) also found an eastward dispersal asymmetry in trans-Tasman dispersal, although the sample size was too small for significance testing. Our data set is not exhaustive, but it does include lineages with a broad array of life histories, dispersal strategies and ecological tolerances - from lowland forest trees to alpine herbs. Furthermore, age estimates suggest that inferred events have occurred over a broad time period. Together these observations suggest that asymmetry in trans-Tasman dispersal may have been a general phenomenon over relatively long time periods.

Although trans-Tasman dispersal is predominantly eastward, we also inferred westward dispersal (e.g. in Ranunculus, Aciphylla). Such dispersals have previously been explained in terms of anticyclones that form to the south of Australia and produce easterly wind flows between New Zealand and
Figure 8 Map of the Southern Hemisphere showing frequencies of inferred dispersal events between Australia, South America and New Zealand estimated from our entire data set. The arrow thickness corresponds approximately to the frequency of the event type. Frequencies are the number of dispersal events required to explain the fit between the organismal phylogenies and the GAC (Fig. 4) if all areas were equally well represented in the data set.

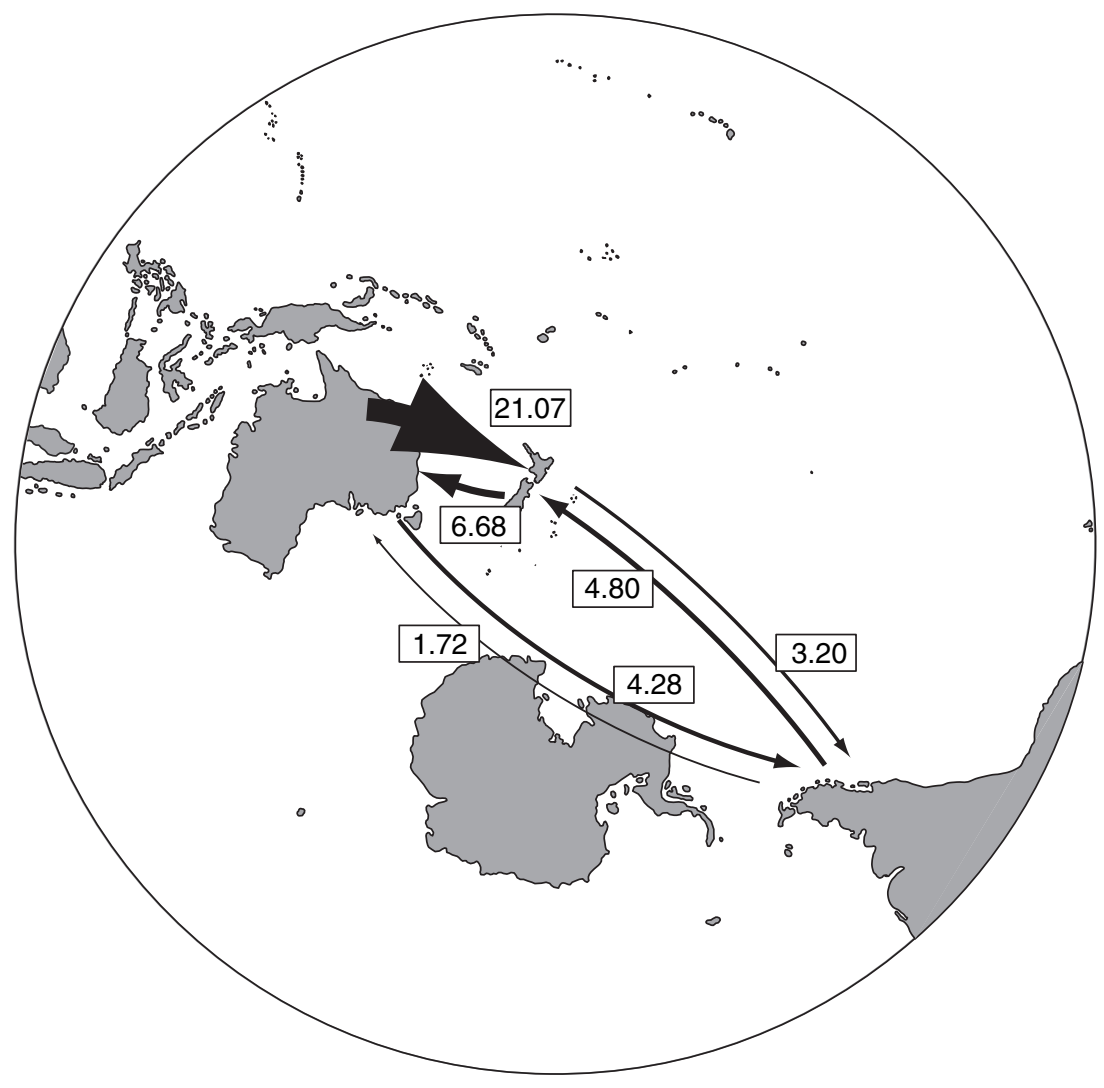


Australia (Wardle, 1978). Whatever the underlying explanation, the inference of westward dispersal suggests that circumpolar currents do not impose absolute constraints in dispersal direction - the WWD and AAC have been important mediators of trans-Tasman dispersal but there have been opportunities for dispersal against them.

\section{Dispersal between New Zealand and South America}

The direction of circumpolar currents predicts predominantly eastward dispersal from New Zealand to South America. However, in our analyses asymmetry in inferred dispersal is not consistent with WWD- or AAC-mediated transport. Specifically, dispersal between New Zealand and South America was more frequently inferred to be westward (Fig. 8), although this asymmetry was not statistically significant. This result raises an interesting question - why, if trans-Tasman dispersal exhibits asymmetry, would New Zealand-South America dispersal not show a similar pattern since we also expect these events to be influenced by circumpolar currents? There are at least two possible explanations for our failure to detect significant patterns. Potentially the result reflects insufficient sample size. Phylogenies that include South American taxa are underrepresented in available studies - perhaps there are too few inferred events and we need additional phylogenies before we can detect significant patterns. However, note that Sanmartín \& Ronquist (2004) identified a statistically significant level of westward dispersal. The alternative is that for New ZealandSouth American events, dispersal is as likely to be eastward as it is to be westward (or at least the frequencies are more similar to one another than for trans-Tasman events).

\section{Comparing pattern and process: a possible explanation}

Observed differences in dispersal asymmetry may partly be explained by the relative connectedness of the areas. New Zealand and Australia are geographically much closer to one another than to South America. Furthermore, meteorological data indicate stronger and more consistent wind connections between Australia and New Zealand than across the southern Pacific Ocean (Muñoz et al., 2004). We do not suggest that direct dispersal from New Zealand to South America is impossible or has not occurred (e.g. water-borne dispersal may be less influenced) but simply that shorter movements between strongly connected areas may be more likely than longer events between areas with weaker connections. A further difference is the possibility for overland dispersal. Several authors have suggested that until relatively recently Antarctica acted as a stepping-stone for dispersal from South America to New Zealand (Swenson \& Bremer, 1997; Renner et al., 2000; Wagstaff et al., 2006). However, there seems little reason why Antarctica could not also have provided a route for eastward movements from New Zealand to South America. If so then perhaps we should not expect strong asymmetry in dispersal certainly circumpolar currents could have influenced movements to and from Antarctic but once on the continent dispersal is not likely to reflect these currents. Such a landbased route has not been available for trans-Tasman dispersal. Some authors have suggested that islands along the Lord Howe Rise may have provided a stepping-stone route across the Tasman Sea (Linder \& Crisp, 1995). Although certainly possible, any transport along such an island chain may well have been influenced by circumpolar currents.

We should also consider the possibility that dispersal may not have followed the commonly expected routes or that other modes have been important. For example, New Zealand-South America dispersal has traditionally been discussed in a transPacific context because this is the shortest route. However, if movements from South America to New Zealand were via the Atlantic and Indian Oceans then exclusively eastward dispersal could provide an explanation of the observed patterns. In this case, rather than explaining how seeds or spores might disperse against the circumpolar currents we need to evaluate whether these flows could have mediated even longer dispersal events. Bird dispersal may also provide an important mechanism for transporting propagules in the Southern Hemisphere. Large seabirds regularly migrate between the southern continents and could carry seeds with them (Moore, 1972). Indeed, given that historically bird populations were much larger, this may have represented an important mode of transport. In particular, bird dispersal may help to explain very long-distance events for seeds that lack obvious adaptations to wind dispersal as well as very long-distance events (e.g. western Pacific-South America) and those that are inconsistent with the direction of circumpolar currents.

As Cook \& Crisp (2005a) suggest, it is critical to consider process when inferring historical biogeography. In this case, comparing potential processes suggests important differences between trans-Tasman and New Zealand-South America dispersal. Furthermore, although we have not specifically addressed the Australia-South America situation here, we suggest that with respect to modes and routes these events are likely to be very similar to New Zealand-South America dispersal. Clearly, if we do not consider the diversity of possible dispersal processes then our inferences will potentially be misled. Concerted dispersal has been important for shaping Southern Hemisphere distribution patterns, but it is important to recognize the complexity of the situation rather than a priori assume an explanation. Our current understanding of dispersal processes is still fragmentary and we need to understand the underlying mechanisms in much more detail. For example, we need to know at what times current systems were stronger or weaker (e.g. Theide, 1979) or the frequency of suitable conditions (e.g. Close et al., 1978). Only once we have a better understand of dispersal process will it be possible to apply realistic estimates of dispersal frequency and asymmetry to biogeographical reconstructions.

\section{Future prospects}

There is compelling phylogenetic evidence for the importance of dispersal in shaping Southern Hemisphere plant distribu- 
tion patterns. Indeed, we have sufficient data to begin testing more detailed hypotheses on dispersal processes. Our analyses provide insights, but it is clear that a larger, more complete data set is still needed. Thorne (1972) lists at least 50 plant lineages that occur in Australia, New Zealand and South America, with many others shared by two of these areas. In order to understand Southern Hemisphere plant dispersal more fully, we will need to include many more of these lineages in future analyses. Expanding the data set may also allow us to explore the patterns associated with the smaller landmasses (e.g. New Caledonia, sub-Antarctic island groups). Currently limited sampling prevents such analyses but testing the relationships of these areas will be important for understanding the details of Southern Hemisphere plant biogeography.

Of greater general importance for biogeography will be the ongoing development of analytical tools. Current approaches are useful, but in order to address detailed hypotheses we need to extend present methods and add new approaches. One important avenue will be incorporating truly mixed dispersal-vicariance models (de Queiroz, 2005). Currently available methods either favour vicariance and duplication as explanations (e.g. DIVA, parsimony-based tree fitting) or completely ignore vicariance (e.g. Nepokroeff et al., 2003). However, it is clear that neither of these approaches is suitable in all situations and we need methods that incorporate both processes more realistically. New methods will need to go beyond trees and extant geographical ranges to consider a wider range of data. Indeed, it is widely recognized that integrating additional data sources is critical for further improving biogeographical inference (e.g. Donoghue \& Moore, 2003). Recent attention has focused on divergence time estimates. Currently these are used a posteriori, and while this approach is useful it would be preferable to have methods that explicitly incorporate time. For example, TREEFITTER could be modified so that vicariance would only be inferred if branching in the TAC and GAC was congruent in pattern and timing (F. Ronquist, personal communication). It will also be important to incorporate other information - for example, ancestral geographical ranges based on fossil taxa or estimates of dispersal frequency and direction. The next decade will be an exciting time for historical biogeography as our data sets and analytical methods improve.

\section{ACKNOWLEDGEMENTS}

We thank Robert McDowall, Richard Ree, Fredrik Ronquist and two anonymous referees for their comments on earlier versions of the manuscript. I.S. is supported by the Swedish Science Research Council (GRANT 621-2003-456). R.C.W. is supported by the Fundação de Amparo à Pesquisa do Estado de São Paulo (Grant 04/09666-2)

\section{REFERENCES}

Axelrod, D.I. (1992) Climatic pulses, a major factor in legume evolution. Advances in legume systematics, Part 4 (ed. by P.S.
Herendeen and D.L. Dilcher), pp. 259-279. Royal Botanical Garden, Kew.

Barnes, R.W. \& Jordan, G.J. (2000) Eucryphia (Cunoniaceae) reproductive and leaf macrofossils from Australian Cainozoic sediments. Australian Systematic Botany, 13, 373-394.

Baum, D.A., Small, R.L. \& Wendel, J.F. (1998) Biogeography and floral evolution of baobabs (Adansonia, Bombaceae) as inferred from multiple data sets. Systematic Biology, 47, 181207.

Bradford, J.C. (2002) Molecular phylogenetics and morphological evolution in Cunonieae (Cunoniaceae). Annals of the Missouri Botanical Garden, 89, 491-503.

Bradford, J.C. \& Barnes, R.W. (2001) Phylogenetics and classification of Cunoniaceae (Oxalidales) using chloroplast DNA sequences and morphology. Systematic Botany, 26, 354-385.

Breitwieser, I., Glenny, D.S., Thorne, A. \& Wagstaff, S.J. (1999) Phylogenetic relationships in Australasian Gnaphalieae (Compositae) inferred from ITS sequences. New Zealand Journal of Botany, 37, 399-412.

Bremer, K. (2002) Gondwanan evolution of the grass alliance of families (Poales). Evolution, 56, 1374-1387.

Bremer, K., Friis, E.M. \& Bremer, B. (2004) Molecular phylogenetic dating of asterids flowering plants shows early Cretaceous diversification. Systematic Biology, 53, 496-505.

Buckley, T.R., Arensburger, P., Simon, C. \& Chambers, G.K. (2002) Combined data, Bayesian phylogenetics, and the origin of the New Zealand cicada genera. Systematic Biology, 51, 4-18.

Chacón, J., Madriñán, S., Chase, M.W. \& Bruhl, J.J. (2006) Molecular phylogenetics of Oreobolus (Cyperaceae) and the origin and diversification of the American species. Taxon, 55, 359-366.

Close, R.C., Moar, N.T., Tomlinson, A.I. \& Lowe, A.D. (1978) Aerial dispersal of biological material from Australia to New Zealand. International Journal of Biometeorology, 22, 1-19.

Coode, M.J.E. (1985) Aristotelia and Vallea, closely related in Elaeocarpaceae. Kew Bulletin, 40, 479-507.

Cook, L.G. \& Crisp, M.D. (2005a) Directional asymmetry of long-distance dispersal and colonization could mislead reconstructions of biogeography. Journal of Biogeography, 32, 741-754.

Cook, L.G. \& Crisp, M.D. (2005b) Not so ancient: the extant crown group of Nothofagus represents a post-Gondwanan radiation. Proceedings of the Royal Society of London Series B, Biological Sciences, 272, 2535-2544.

Croizat, L., Nelson, G. \& Rosen, D.E. (1974) Centres of origin and related concepts. Systematic Zoology, 23, 265-287.

Cunningham, C.W. (1999) Some limitations of ancestral character-state reconstructions when testing evolutionary hypotheses. Systematic Biology, 48, 665-674.

Dettmann, M.E., Pocknall, D.T., Romero, E.J. \& Zamaloa, M.C. (1990) Nothofagidites Erdtman ex Potonié, 1960; A catalogue of species with notes on the palaeogeographic distribution of Nothofagus BI (southern beech). New Zealand Geological Survey Palaeontological Bulletin, 60, 1-79. 
Donoghue, M.J. \& Moore, B.R. (2003) Toward an integrative approach in historical biogeography. Integrative \& Computational Biology, 43, 261-270.

Doyle, J.A. (2000) Paleobotany, relationships, and geographic history of Winteraceae. Annals of the Missouri Botanical Garden, 87, 303-316.

Fell, H.B. (1962) West-Wind Drift dispersal of echinoderms in the Southern Hemisphere. Nature, 24, 759-761.

Gemmill, C.E.C., Allan, G.J., Wagner, W.L. \& Zimmer, E.A. (2002) Evolution of insular Pacific Pittosporum (Pittosporaceae): origin of the Hawaiian radiation. Molecular Phylogenetics and Evolution, 22, 31-42.

Gradstein, F.M. \& Ogg, J.G. (2004) Geologic time scale 2004. International Commission of Stratigraphy. Available at: http://www.stratigraphy.org.

von Hagen, K.B. \& Kadereit, J.W. (2001) The phylogeny of Gentianella (Gentianaceae) and its colonization of the southern hemisphere as revealed by nuclear and chloroplast DNA sequence variation. Organisms, Diversity \& Evolution, 1, 61-79.

van der Hammen, T. (1979) History of the flora, vegetation and climate in the Cordillera Oriental during the last five million years. Tropical botany (ed. by K. Larsen and L.B. Holm-Nielsen), pp. 25-32. Academic Press, London.

Hatch, E. (1951) Checklist of the New Zealand orchids. Tuatara, 4, 28-40.

Hatch, E. (1952) The New Zealand forms of Thelymitra. J. R. et G. Forster and appendices. Part I. Transactions of the Royal Society of New Zealand, 79, 386-402.

Heads, M. (1999) Vicariance biogeography and terrane tectonics in the South Pacific: analysis of the genus Abrotanella (Compositae). Biological Journal of the Linnean Society, 67, 391-432.

Hooker, J.D. (1853) Botany of the Antarctic Voyage of the Discovery Ships 'Erebus' and 'Terror' in the Years 1831-1843. II. Flora Novae-Zelandiae. Part I. Flowering plants. Lovell Reeve, London.

Humphries, C.J. \& Parenti, L. (1999) Cladistic biogeography: interpreting patterns of plant and animal distribution. Oxford University Press, New York.

Juan, C., Emerson, B.C., Oromí, P. \& Hewitt, G.M. (2000) Colonization and diversification: towards a phylogeographic synthesis for the Canary Islands. Trends in Ecology \& Evolution, 15, 104-109.

Kårehed, J., Lundberg, J., Bremer, B. \& Bremer, K. (1999) Evolution of the Australasian families Alseuosmiaceae, Argophyllaceae, and Phellinaceae. Systematic Botany, 24, 660-682.

Karol, K.G., Suh, Y., Schaltz, G.E. \& Zimmer, E.A. (2000) Molecular evidence for the phylogenetic position of Takhtajania in the Winteraceae: inference from nuclear ribosomal and chloroplast gene spacer sequences. Annals of the Missouri Botanical Garden, 87, 414-432.

Knapp, M., Stöckler, K., Havell, D., Delsuc, F., Sebastiani, F. \& Lockhart, P.J. (2005) Relaxed molecular clock provides evidence for long-distance dispersal of Nothofagus (southern beech). PLOS Biology, 3, e14.

Lavin, M., Herendeen, P.S. \& Wojciechowski, M.F. (2005) Evolutionary rates analysis of Leguminosae implicates a rapid diversification of lineages during the Tertiary. Systematic Biology, 54, 575-594.

Linder, H.P. (1999) Rytidosperma vickeryae - a new danthonioid grass from Kosciuszko (New South Wales, Australia): morphology, phylogeny and biogeography. Australian Systematic Botany, 12, 743-755.

Linder, H.P. \& Barker, N.P. (2000) Biogeography of Danthonieae. Grasses: systematics and evolution (ed. by S.W.L. Jacobs and J. Everett), pp. 231-238. CSIRO, Melbourne.

Linder, H.P. \& Crisp, M.D. (1995) Nothofagus and Pacific biogeography. Cladistics, 11, 5-32.

Lockhart, P.J., Mclenachan, P.A., Havell, D., Glenny, D., Huson, D. \& Jensen, U. (2001) Phylogeny, radiation and transoceanic dispersal of New Zealand alpine buttercups: molecular evidence under split decomposition. Annals of the Missouri Botanical Garden, 88, 458-477.

Macphail, M.K. (1997) Comment on M. Pole (1994): 'The New Zealand flora - entirely long-distance dispersal?'. Journal of Biogeography, 21, 625-635.

Magallon, S., Crane, P.R. \& Herendeen, P.S. (1999) Phylogenetic pattern, diversity, and diversification of eudicots. Annals of the Missouri Botanical Garden, 86, 297-372.

Manos, P.S. (1997) Systematics of Nothofagus (Nothofagaceae) based on rDNA spacer sequences (ITS): taxonomic congruence with morphology and plastid sequences. American Journal of Botany, 84, 1137-1155.

McCarthy, D. (2003) The trans-Pacific zipper effect: disjunct sister taxa and matching geological outlines that link the Pacific margins. Journal of Biogeography, 30, 15451561.

McDowall, R.M. (2004) What biogeography is: a place for process. Journal of Biogeography, 31, 345-351.

McGlone, M.S. (2005) Goodbye Gondwana. Journal of Biogeography, 32, 739-740.

McLoughlin, S. (2001) The break up history of Gondwana and its impact on pre-Cenozoic floristic provincialism. Australian Journal of Botany, 49, 271-300.

Mildenhall, D. (1980) New Zealand Late Cretaceous and Cenozoic plant biogeography - a contribution. Palaeogeography, Palaeoclimatology, Palaeoecology, 31, 197-233.

Molvray, M., Kores, P.J. \& Chase, M.W. (1999) Phylogenetic relationships within Korthalsella (Viscaceae) based on nuclear ITS and plastid TRNL-F sequence data. American Journal of Botany, 86, 249-260.

Moore, D.M. (1972) Connections between cool temperate floras with particular reference to southern South America. Taxonomy, phytogeography, and evolution (ed. by D.H. Valentine), pp. 115-138. Academic Press, London.

Morrone, J.J. \& Crisci, J.V. (1995) Historical biogeography: introduction to methods. Annual Review of Ecology and Systematics, 26, 373-401. 
Muller, J. (1981) Fossil pollen records of extant angiosperms. Botanical Review, 47, 1-142.

Muñoz, J., Felicísimo, A.M., Cabezas, F., Burgaz, A.R. \& Martínez, I. (2004) Wind as a long-distance dispersal vehicle in the Southern Hemisphere. Science, 304, 1144-1147.

Nathan, R. (2006) Long-distance dispersal of plants. Science, 313, 786-788.

Nelson, G. \& Ladiges, P.Y. (2001) Gondwana, vicariance biogeography and the New York school revisited. Australian Journal of Botany, 49, 389-409.

Nelson, G. \& Platnick, N.I. (1981) Systematics and biogeography: cladistics and vicariance. Columbia University Press, New York.

Nepokroeff, M., Sytsma, K.J., Wagner, W.L. \& Zimmer, E.A. (2003) Reconstructing ancestral patterns of colonization and dispersal in the Hawaiian understorey tree genus Psychotria (Rubiaceae): a comparison of parsimony and likelihood approaches. Systematic Biology, 52, 820-838.

Oliver, W.R.B. (1928) The flora of the Waipoa Series (Late Pliocene) of New Zealand. Transactions and Proceedings of the New Zealand Institute, 59, 287-303.

Pole, M. (1994) The New Zealand flora - entirely long-distance dispersal? Journal of Biogeography, 21, 625-635.

Pole, M.S. (2001) Can long-distance dispersal be inferred from the New Zealand fossil record? Australian Journal of Botany, 49, 357-366.

Poole, I. \& Gottwald, H. (2001) Monimiaceae sensu lato, an element of Gondwanan polar forests: evidence from the Late Cretaceous-Early Tertiary wood flora of Antarctica. Australian Systematic Botany, 14, 207-230.

Poole, I., Cantrill, D.J., Hayes, P. \& Francis, J. (2000) The fossil record of Cunoniaceae: new evidence from Late Cretaceous wood of Antarctica? Review of Palaeobotany and Palynology, 11, 127-144.

de Queiroz, A. (2005) The resurrection of oceanic dispersal in historical biogeography. Trends in Ecology \& Evolution, 20, 68-73.

Radford, E.A., Watson, M.F. \& Preston, J. (2001) Phylogenetic relationships of species of Aciphylla (Apiaceae, subfamily Apioideae) and related genera using molecular, morphological, and combined data sets. New Zealand Journal of Botany, 39, 183-208.

Raven, P.H. (1973) Evolution of subalpine and alpine plant groups in New Zealand. New Zealand Journal of Botany, 11, 177-200.

Ree, R.H. \& Donoghue, M.J. (1999) Inferring rates of change in flower asymmetry in asteroid phylogenies. Systematic Biology, 48, 633-641.

Ree, R.H., Moore, B.R., Webb, C.O. \& Donoghue, M.J. (2005) A likelihood framework for inferring the evolution of geographic range on phylogenetic trees. Evolution, 59, 22992311.

Renner, S.S., Foreman, D.B. \& Murray, D. (2000) Timing transantarctic disjunctions in the Atherospermataceae (Laurales): evidence from coding and noncoding chloroplast sequences. Systematic Biology, 49, 579-591.
Riddle, B.R. (2005) Is biogeography emerging from its identity crisis? Journal of Biogeography, 32, 185-186.

Ronquist, F. (1998) Phylogenetic approaches in coevolution and biogeography. Zoologica Scripta, 26, 313-322.

Ronquist, F. (2003a) Parsimony analysis of coevolving species associations. Cospeciation (ed. by R.D.M. Page), pp. 22-64. Chicago University Press, Chicago.

Ronquist, F. (2003b) TreeFitter version 1.2. Available from http://www.ebc.uu.se/systzoo/research/treefitter/treefitter.html.

Ronquist, F. \& Nylin, S. (1990) Process and patterns in the evolution of species associations. Systematic Zoology, 39, 323-344.

Sanmartín, I. (2006) Event-based biogeography: integrating patterns, processes, and time. Biogeography in a changing world (ed. by M.C. Ebach and R.S. Tangney), pp. 135-159. Taylor \& Francis, London.

Sanmartín, I. \& Ronquist, F. (2002) New solutions to old problems: widespread taxa, redundant distributions and missing areas in event-based biogeography. Animal Biodiversity and Conservation, 25, 75-93.

Sanmartín, I. \& Ronquist, F. (2004) Southern Hemisphere biogeography inferred by event-based models: plant versus animal patterns. Systematic Biology, 53, 216-243.

Sanmartín, I., Enghoff, H. \& Ronquist, F. (2001) Patterns of animal dispersal, vicariance and diversification in the Holarctic. Biological Journal of the Linnean Society, 73, 345390.

de Saporta, G. (1865) Etudes sur la vegetation du Sud-Est de la France a l'epoque tertiare, 2 (3). Annales des Sciences Naturelles Botanique Series, 5, 212-217.

Skottsberg, C. (1960) Remarks on the plant geography of the southern cold temperate zone. Proceedings of the Royal Society of London Series B, Biological Sciences, 152, 447-457.

Swenson, U. \& Bremer, K. (1997) Pacific biogeography of the Asteraceae genus Abrotanella (Senecioneae, Blennospermatinae). Systematic Botany, 22, 493-508.

Swenson, U., Backlund, A., McLoughlin, S. \& Hill, R.S. (2001) Nothofagus biogeography revisited with special emphasis on the enigmatic distribution of subgenus Brassospora in New Caledonia. Cladistics, 17, 28-47.

Templeton, A.R. (1998) Nested clade analyses of phylogeographic data: testing hypotheses about gene flow and population history. Molecular Ecology, 7, 381-397.

Theide, J. (1979) Wind regimes over the late Quaternary southwest Pacific Ocean. Geology, 7, 259-262.

Thorne, R.F. (1972) Major disjunctions in the geographic ranges of seed plants. The Quarterly Review of Biology, 47, 365-411.

Tiffney, B.H. (1985) Perspectives on the origin of the floristic similarity between eastern Asia and eastern North America. Journal of the Arnold Arboretum, 66, 73-94.

Veevers, J.J., Powell, C.McA. \& Roots, S.R. (1991) Review of sea floor spreading around Australia. I. Synthesis of the patterns of spreading. Australian Journal of Earth Sciences, 38, 373-389. 
Vences, M., Freyhoff, J., Sonnenberg, R., Kosuch, J. \& Veith, M. (2001) Reconciling fossils and molecules: Cenozoic divergence of cichlid fishes and the biogeography of Madagascar. Journal of Biogeography, 28, 1091-1099.

Wagstaff, S.J. \& Dawson, M.I. (2000) Classification, origin, and patterns of diversification of Corynocarpus (Corynocarpaceae) inferred from DNA sequences. Systematic Botany, 25, 134-149.

Wagstaff, S.J. \& Garnock-Jones, P.J. (2000) Patterns of diversification in Chionohebe and Parahebe (Scrophulariaceae) inferred from ITS sequences. New Zealand Journal of Botany, 38, 389-407.

Wagstaff, S.J. \& Wege, J. (2002) Patterns of diversification in New Zealand Stylidiaceae. American Journal of Botany, 89, 865-874.

Wagstaff, S.J., Heenan, P.B. \& Sanderson, M.J. (1999) Classification, origins, and patterns of diversification in $\mathrm{New}$ Zealand Carmichaelinae (Fabaceae). American Journal of Botany, 86, 1346-1356.

Wagstaff, S.J., Martinsson, K. \& Swenson, U. (2000) Divergence estimates of Tetrachondra hamiltonii and T. patagonica (Tetrachondraceae) and their implications for austral biogeography. New Zealand Journal of Botany, 38, 587-596.

Wagstaff, S.J., Bayly, M.J., Garnock-Jones, P.J. \& Albach, D.C. (2002) Classification, origin, and diversification of the New Zealand hebes (Scrophulariaceae). Annals of the Missouri Botanical Garden, 89, 38-63.

Wagstaff, S.J., Breitwieser, I. \& Swenson, U. (2006) Origin and relationships of the austral genus Abrotanella (Asteraceae) inferred from DNA sequences. Taxon, 55, 95-106.

Wanntorp, L. \& Wanntorp, H.E. (2003) The biogeography of Gunnera. (Gunneraceae): vicariance and dispersal. Journal of Biogeography, 30, 979-987.

Wardle, P. (1978) Origins of the New Zealand mountain flora, with special reference to trans-Tasman relationships. New Zealand Journal of Botany, 16, 535-550.

Wares, J.P., Gaines, S.D. \& Cunningham, C.W. (2001) A comparative study of asymmetric migration events across a marine biogeographic boundary. Evolution, 55, 295306.

Waters, J.M., Dijkstra, L.H. \& Wallis, G.P. (2000) Biogeography of a Southern Hemisphere freshwater fish: how important is marine dispersal? Molecular Ecology, 9, 18151821.

Winkworth, R.C., Robertson, A.W., Grau, J. \& Lockhart, P.J. (2002a) The origins and evolution of the genus Myosotis (Boraginaceae). Molecular Phylogenetics and Evolution, 24, 180-193.
Winkworth, R.C., Wagstaff, S.J., Glenny, D. \& Lockhart, P.J. (2002b) Plant dispersal N.E.W.S. from New Zealand. Trends in Ecology \& Evolution, 17, 514-520.

Woodburne, M.O. \& Case, J.A. (1996) Dispersal, vicariance, and the Late Cretaceous to Early Tertiary land mammal biogeography from South America to Australia. Journal of Mammalian Evolution, 3, 121-161.

Yokoyama, J., Suzuki, M., Iwatsuki, K. \& Hasebe, M. (2000) Molecular phylogeny of Coriaria, with special emphasis on the disjunct distribution. Molecular Phylogenetics and Evolution, 14, 11-19.

\section{SUPPLEMENTARY MATERIAL}

The following supplementary material is available for this article

Appendix S1. Input file for analysis with treEFItTER.

This material is available as part of the online article from: http://www.blackwell-synergy.com/http://www.blackwell-synergy.com/doi/abs/10.1111/j.1365-2699.2006.01655.x (This link will take you to the article abstract).

Please note: Blackwell Publishing are not responsible for the content or functionality of any supplementary materials supplied by the authors. Any queries (other than missing material) should be directed to the corresponding author for the article.

\section{BIOSKETCHES}

Isabel Sanmartín is an assistant professor at the Department of Systematic Zoology, Uppsala University. Her main research interests include the study of large-scale historical biogeographical patterns and the development of new methods of biogeographical inference.

Livia Wanntorp is a plant systematist associated with the Department of Botany, Stockholm University. Her fields of research include systematics and biogeography of several eudicot families, such as Gunneraceae, Sabiaceae and Apocynaceae.

Richard C. Winkworth has broad interests in phylogenetics and systematics. His current research focuses on understanding the geographical distribution of present-day plant species diversity at various spatial and temporal scales.

Editor: Robert McDowall 